\title{
A New Insitu Technique for Measuring the Concentration of Lubricant on a Boiling Heat Transfer Surface
}

Mark A. Kedzierski

National Institute of Standards and Technology

Building and Fire Research Laboratory

Gaithersburg, MD 20899

Thomas J. Bruno and Matt B. O'Neill

Physical and Chemical Properties Division

National Institute of Standards and Technology

Boulder, CO

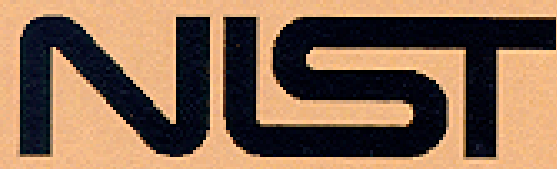

United States Department of Commerce Technology Administration

National Institute of Standards and Technology 


\section{A New Insitu Technique for Measuring the Concentration of Lubricant on a Boiling Heat Transfer Surface}

M.A. Kedzierski

T.J. Bruno and M. B. O'Neill

January 1998

Building and Fire Research Laboratory

National Institute of Standards and Technology

Gaithersburg, MD 20899

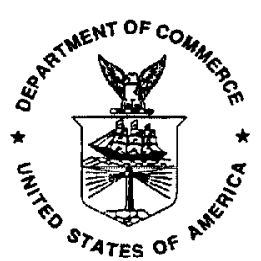

U.S. Department of Commerce

William M. Daley, Secretary

U.S. Department of Energy

Technology Administration

Washington, D.C., 20858

Mary L. Good, Under Secretary for Technology

National Institute of Standards and Technology

Raymond G. Kammer, Director 


\section{TABLE OF CONTENTS}

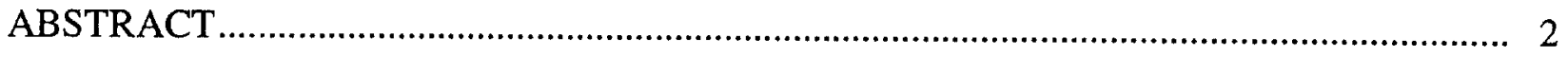

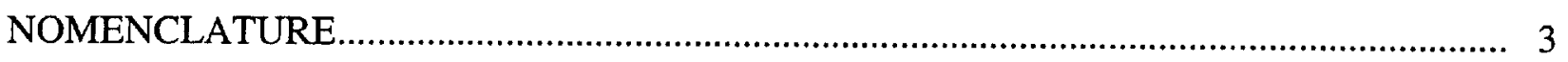

INTRODUCTION

ABSORPTION AND FLUORESCENCE SPECTRA .......................................................... 7 Absorption (7); Fluorescence (9)

SPECTRAL MEASUREMENT FROM THE TARGET …................................................ 10

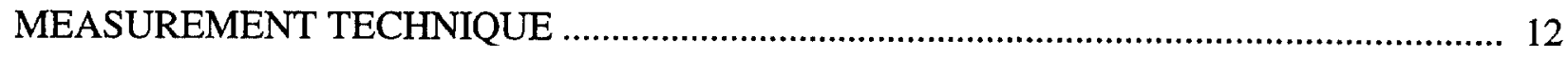

APPLICATION OF MEASUREMENT TECHNIQUE …................................................ 15

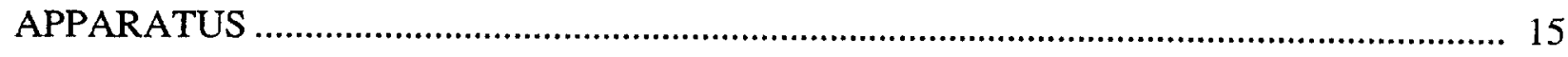

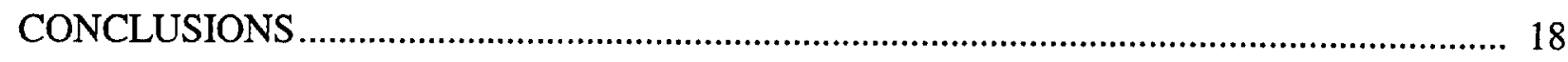

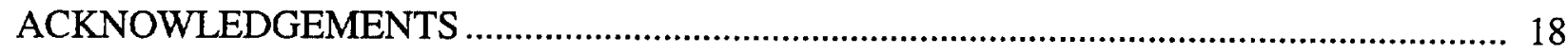

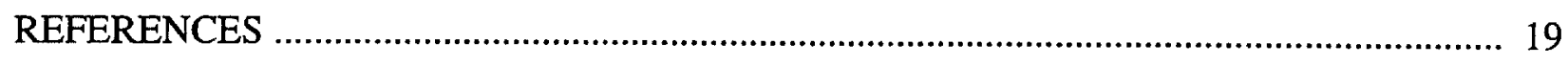

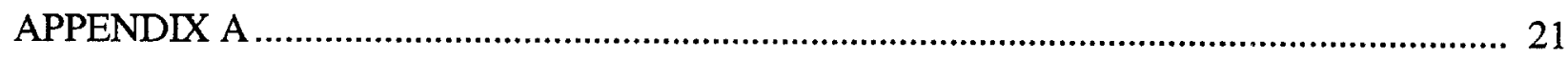

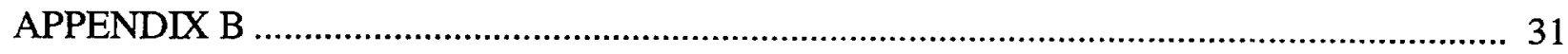




\begin{abstract}
This paper presents a technique for using the fluorescent properties and/or the harmonic focusing properties of several commercial lubricants to measure the concentration of lubricant on an aluminum vignetting target. The measurement method is being developed to determine the concentration of lubricant insitu on a boiling heat transfer surface. The heat transfer performance of a boiling surface is a strong function of both the type of lubricant and its concentration in the refrigerant. In general, severe boiling performance degradations may occur for higher concentrations of lubricant on the surface. The lubricant is preferentially drawn out of the bulk refrigerant/lubricant mixture by the boiling process and accumulates on the surface in excess of the bulk concentration. However, different lubricants accumulate on the heat transfer surface by different amounts for the same bulk concentration. The excess lubricant resides in a very thin layer on the surface. Accordingly, the ability to measure the lubricant concentration on the heat transfer surface would lead to a fundamental understanding of the mechanism by which lubricants can degrade or improve boiling performance. The lubricant concentration on a vignetting target was found to be linear with respect to the fluorescence intensity and the reflected harmonic from the surface. Consequently, the results of this study have shown that it is feasible to use the fluorescence and reflected harmonic measured from a boiling heat transfer surface to obtain the concentration of lubricant on the surface.
\end{abstract}

Keywords: boiling, refrigerant/lubricant mixtures, fluorescence, absorption, reflected harmonic, enhanced, heat transfer, alternative refrigerants 
NOMENCLATURE

English Symbols

C molar concentration of the solute

$\mathrm{D}_{\mathrm{b}} \quad$ departure bubble diameter $(\mathrm{m})$

$\mathrm{L}_{\mathrm{y}} \quad$ length of test surface $(\mathrm{m})$

q" average wall heat flux $\left(\mathrm{W} / \mathrm{m}^{2}\right)$

R gas constant $(8.314 \mathrm{~J} / \mathrm{K} \cdot \mathrm{mol})$

$r_{c} \quad$ radius of cavity mouth $(\mathrm{m})$

$\mathrm{T}$ temperature $(\mathrm{K})$

$\mathrm{T}_{\mathrm{w}}$ temperature of surface at root of fin $(\mathrm{K})$

$\mathrm{x}$ test surface coordinate, Fig. $10(\mathrm{~m})$

y test surface coordinate, Fig. $10(\mathrm{~m})$

Greek symbols

$\beta \quad$ contact angle (rad)

$\Gamma \quad$ surface excess concentration of solute

$\delta_{\mathrm{t}}$ thermal boundary layer thickness (m)

$\Delta \mathrm{T}$ wall superheat: $\mathrm{T}_{\mathrm{w}}-\mathrm{T}_{\mathrm{s}},(\mathrm{K})$

$\lambda$ wavelength

$\sigma \quad$ surface-tension $\left(\mathrm{kg} / \mathrm{m} \bullet \mathrm{s}^{2}\right)$

$\underline{\text { Subscripts }}$

$\begin{array}{ll}\text { exe } & \text { excitation } \\ \mathrm{i} & \text { interface } \\ \mathrm{l} & \text { liquid } \\ \mathrm{m} & \text { mixture } \\ \mathrm{max} & \text { maximum } \\ \mathrm{p} & \text { pure refrigerant } \\ \mathrm{s} & \text { saturated state, solid surface } \\ \mathrm{v} & \text { vapor }\end{array}$




\section{INTRODUCTION}

The heat transfer performance of a boiling surface is a strong function of both the type of lubricant and its concentration in the refrigerant. Figure 1 shows the pool boiling performance of a theoretical refrigerant/lubricant combination for three different lubricant concentrations. The ratio of the mixture heat flux to that obtained for the pure refrigerant

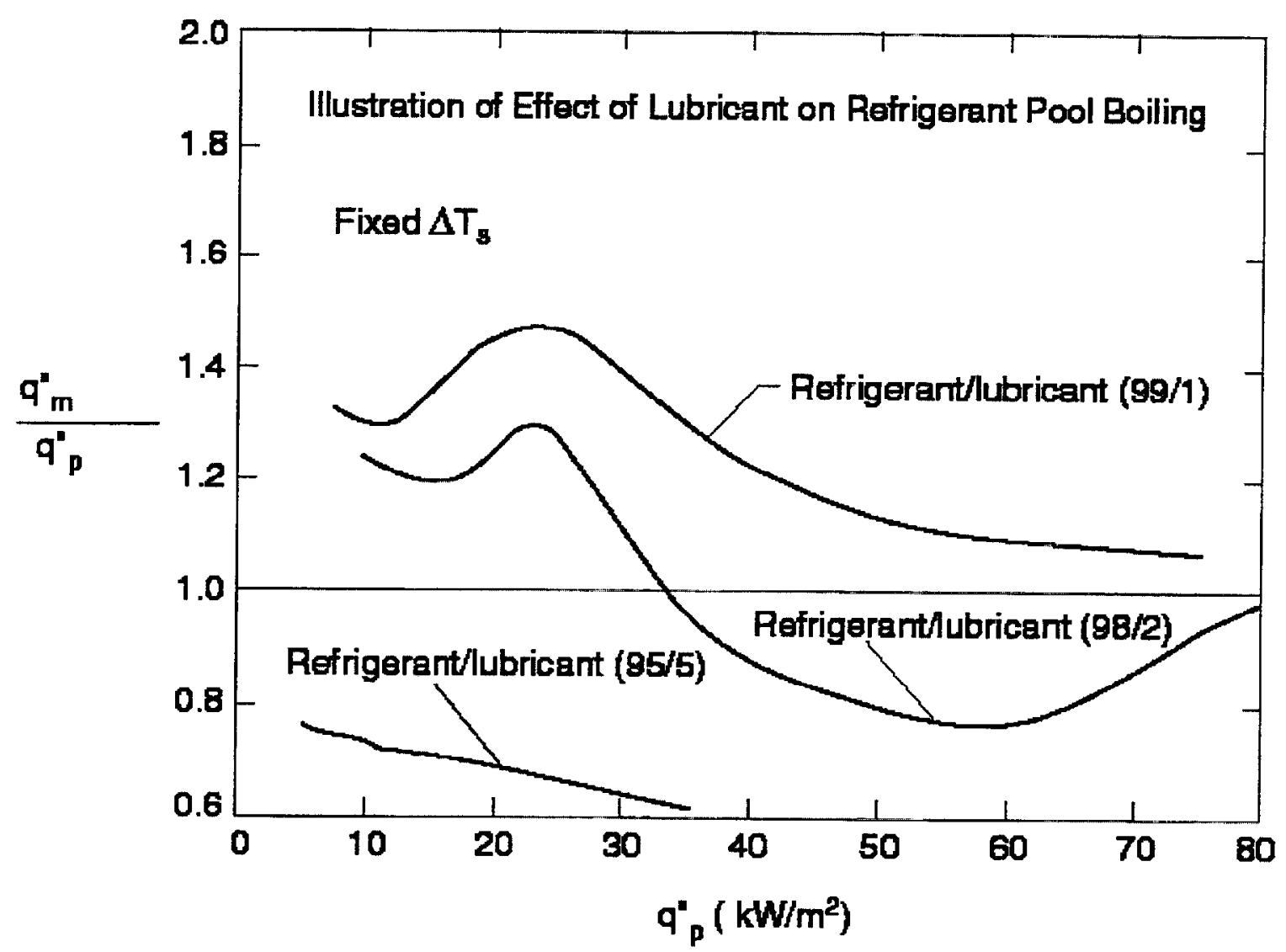

Fig. 1 Illustration of the possible effect of lubricant on the boiling performance of refrigerant

$\left(q{ }_{m} / q "{ }_{p}\right)$ is plotted versus q" in Fig. 1. Enhanced boiling performance may be achieved for lower concentrations of lubricant in refrigerant. As the concentration of lubricant in the refrigerant increases, degradation of the boiling performance is more likely.

It has been speculated that the pool boiling enhancement/degradation mechanism associated with the addition of a lubricant to refrigerant is due to an accumulation of lubricant at the boiling surface (Kedzierski, 1993, and Kedzierski and Kaul, 1993). The excess concentration arises from the relatively low vapor pressure of the lubricant when compared to refrigerant. The lubricant can be locally drawn out of solution as a consequence of refrigerant evaporation. The refrigerant/lubricant liquid mixture travels to the heated wall, 
and the refrigerant preferentially evaporates from the surface leaving behind a liquid phase enriched in lubricant. A balance between deposition and removal of the lubricant establishes some unknown excess concentration of lubricant at the surface. In summary, preferential evaporation of the refrigerant presumably creates a thin lubricant-rich layer on the heated surface.

For refrigerant/lubricant mixture boiling, small bubbles arise from small attractive forces between the lubricant-rich excess layer and the heat transfer surface. Although less heat transfer occurs with a smaller bubble, the site density can be increased as a direct consequence of the small bubble size. An enhancement of the boiling is achieved if the increase in site density more than compensates for the decrease in bubble size. The next few paragraphs provide a more detailed speculative discussion on the enhancement mechanism for refrigerant/lubricant mixture pool boiling.

The refrigerant/lubricant bubbles are small due to the existence of the lubricant-rich excess layer at the boiling surface. For a surface excess concentration of the solute $(\Gamma)$, the Gibbs adsorption equation for a dilute solution (Rosen, 1978) predicts a reduction in the surfacetension between the mixture and the solid surface:

$$
\mathrm{d} \sigma=-\mathrm{RT}_{\mathrm{i}} \Gamma \mathrm{dlnC}
$$

where $R$ is the gas constant, $T_{i}$ is the temperature of the interface, and $C$ is the molar concentration of the solute. If the concentration of the solute (lubricant) is increased above the bulk concentration $(\Gamma \neq 0)$, then the surface-tension $(\sigma)$ between interfacing materials will be lower (negative sign in Gibbs eqn.) than what it would have been if the interface concentration is at the bulk composition. A reduction in the surface-tension between a liquid and a boiling surface will induce a corresponding reduction in the size of the departing bubbles. The surface-tension between the liquid and the solid $\left(\sigma_{\mathrm{ls}}\right)$ determines the magnitude of the bubble attachment force by establishing the magnitude of the contact angle $(\beta)$. This can be demonstrated with the use of the Young and Dupré equation (Adamson, 1967) which is a lateral force balance on a bubble attached to a surface:

$$
\beta=\arccos \left(\frac{\sigma_{\mathrm{vs}}-\sigma_{\mathrm{ls}}}{\sigma_{\mathrm{lv}}}\right)
$$

For fixed surface tension between the liquid and the vapor $\left(\sigma_{l v}\right)$ and the vapor and the solid $\left(\sigma_{\mathrm{vs}}\right)$, a reduction in $\sigma_{\mathrm{ls}}$ causes a reduction in the contact angle $\beta$. The bubble is held to the wall by a surface tension force proportional to $\sigma_{\mathrm{lv}} \sin \beta$. The size of the bubble determines the buoyancy forces on the bubble acting to detach the bubble. A smaller contact angle induces a small bubble attachment force and consequently, a small bubble size. Accordingly, the mixture bubbles are smaller than the pure refrigerant bubbles.

Heuristically, the bubble grows within/on the excess layer, rather than on the solid surface. In the limit, if a bubble were to grow solely on the lubricant-rich layer, the attachment force would be negligible compared to the attachment force for a bubble growing on a solid 
surface. The small attachment force arises from the small difference between the surfacetensions of refrigerant and the lubricant-rich layer (boiling surface). Consequently, the bubble does not hold to the lubricant rich surface as strongly as it does to the solid surface. As a result, the refrigerant/lubricant bubbles are smaller than the pure refrigerant bubbles.

Hsu's (1962) model can be used to show that smaller bubbles will induce higher site densities than larger bubbles. Figure 2 schematically illustrates the proposed site enhancement mechanism by comparing the growth of refrigerant/lubricant and refrigerant bubbles in identical conical cavities. Both bubbles originate below the thermal boundary layer thickness $\left(\delta_{t}\right)$ which exists as a thin layer near the heated surface where $T>T_{s}$. According to Hsu's (1962) model, a site will be active if the bubble is released from the wall before it grows beyond the thermal boundary layer. A bubble that grows beyond $\delta_{\mathrm{t}}$ while attached to the wall condenses and causes the site to be inactive. For a given cavity distribution, more of the larger cavities will be active for the mixture than for the pure refrigerant.

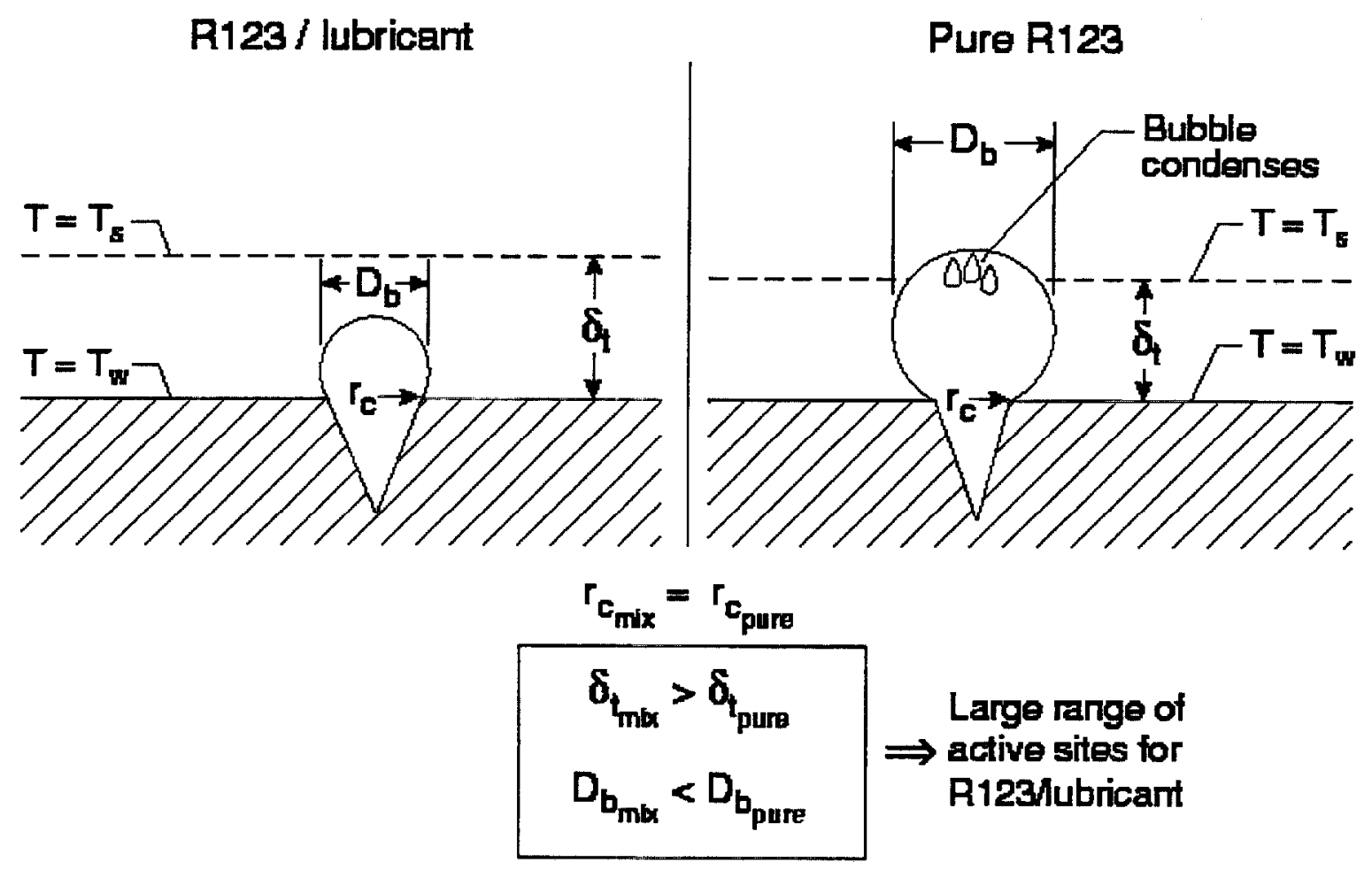

Fig. 2 Site density enhancement model

Although, Fig. 1 shows an enhancement for a mass fraction of $1 \%$ lubricant within the refrigerant, some lubricants exhibit only degradations. Degradations can be exhibited even for very small concentrations of lubricant in the bulk liquid. It is likely that for a given bulk concentration in the same refrigerant, different lubricants will accumulate on the heat transfer surface in different concentrations. It is possible that the lubricant that produced the degradation in the boiling performance may have a stronger affinity for the surface and exist at a higher concentration on the heat transfer surface. Consequently, the 
ability to measure the lubricant concentration on the heat transfer surface would lead to a fundamental understanding of the mechanism by which lubricants can degrade or improve boiling performance. The remainder of the report shows that it may be feasible to use the fluorescence and reflected harmonic measured from a boiling heat transfer surface to obtain the concentration of lubricant on the surface.

\section{ABSORPTION AND FLUORESCENCE SPECTRA}

Light is an electromagnetic wave; it is composed of both electric and magnetic field waves. As a result, light can impose forces on the electrons of molecules which excite them into higher energy states. However, it is primarily the electric field that interacts with the electrons of a molecule. The manner of energy transfer from the electric field is important in determining both the absorption into and the fluorescence from a media. Typically, a particular molecule will absorb incident light of only very specific wavelengths. Also, the energy must be absorbed in such a way that no energy level of the molecule is left only partially filled. The excess energy must be released as photons (or light). The light can be emitted at the same or longer wavelengths than the incident light. If the light emission is at longer wavelengths than the incident light, it is called fluorescence. That is to say, fluorescence occurs at longer wavelengths and lower energies than the absorbed light. Although, the intensity of the fluorescence is at lower energies than the absorbed light, it can still be significant and measurable. It is this intensity which is the signature of the amount of lubricant in the refrigerant.

The characteristics of fluorescence dictate that certain criteria must be met for fluorescence to be useful for measuring lubricant concentration. First, the lubricant must be fluorescent. In fact, the proposed method for determining the concentration of lubricant on a boiling surface relies on the relative fluorescent properties of the lubricant and the refrigerant. Ideally, the lubricant should strongly fluoresce while the refrigerant should not be fluorescent. In this way, the amount of lubricant in the mixture can be calculated from the intensity of the fluorescence emission. Second, the light incident to the lubricant must be of a specific wavelength for absorption to occur. This excitation wavelength can be optimized to produce the greatest fluorescence intensity. Accordingly, the absorption spectra of the lubricant must be measured to determine the excitation wavelength $\left(\lambda_{\text {exe }}\right)$.

\footnotetext{
Absorption

In a preliminary attempt to explore the feasibility of fluorescence detection of compressor lubricants on heat transfer surfaces, the absorption spectra of ten lubricant samples were measured. Table 1 provides a list of the tested lubricants. The lubricants given in Table 1 are typically used by the refrigeration and air-conditioning industry. The UCON lubricant is a mineral oil used with the CFC refrigerants. The Alkylbenzene lubricant was designed for low foaming and is used with low pressure refrigerants. The remaining lubricants (Emkarate and Castrol) are polyol ester lubricants that are compatible with the alternative refrigerants, but specifically designed for use with R134a. Together, the lubricants cover a wide range of viscosities ranging from 20 to $250 \mu \mathrm{m}^{2} / \mathrm{s}$.
} 


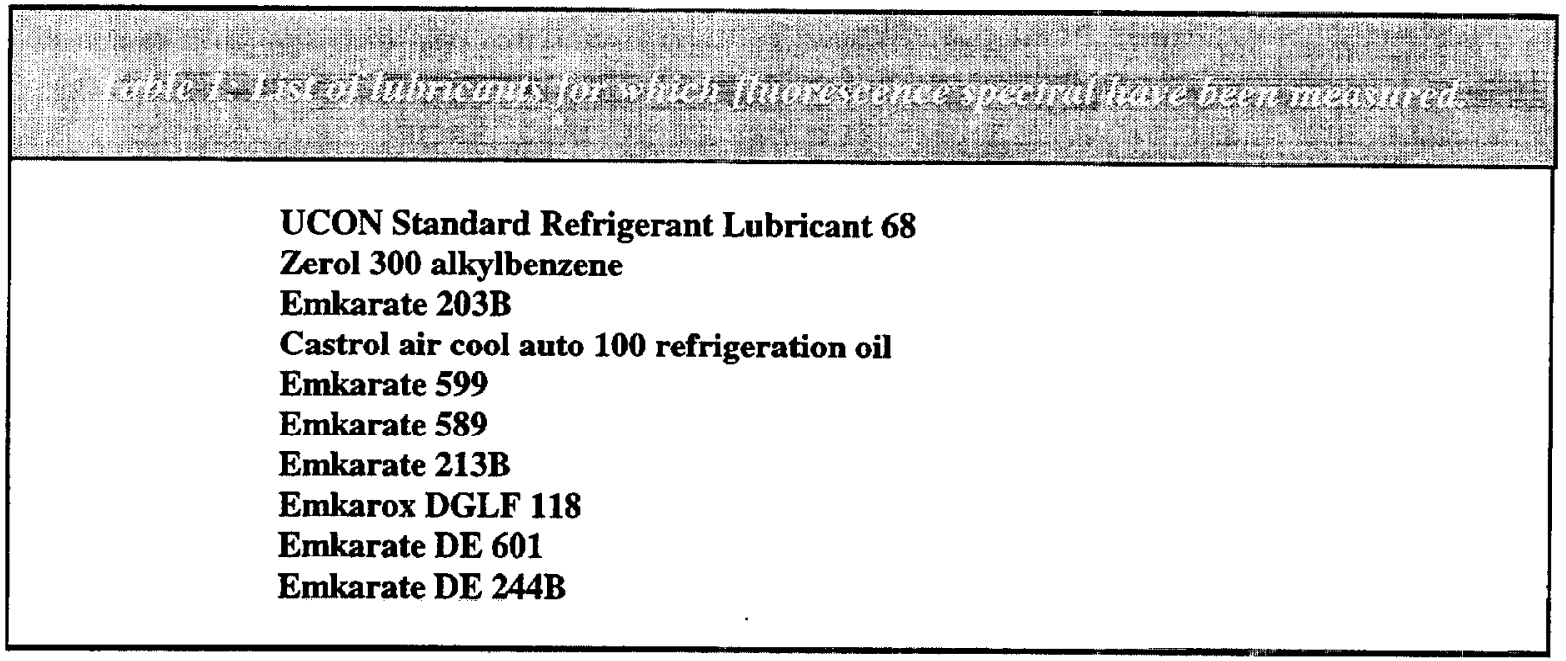

Figure 3 shows a simplified schematic of a spectrophotometer that was used to measure ultraviolet-visible (UV-Vis) absorption spectrum of each lubricant. The excitation light source is focused by a collimating lens into the wavelength selector. The wavelength selector separates the light into its various wavelengths. The slits are adjustable to permit a single or a variable bandwidth of wavelengths incident to the sample cuvette which contains the test media. The test media absorbs a portion of the lights energy and emits the rest to the detector. The galvanometer measures the emergent intensity (I) of the signal. The intensity of the absorbed light is difference between the intensity of the incident light and the intensity of the emergent light.

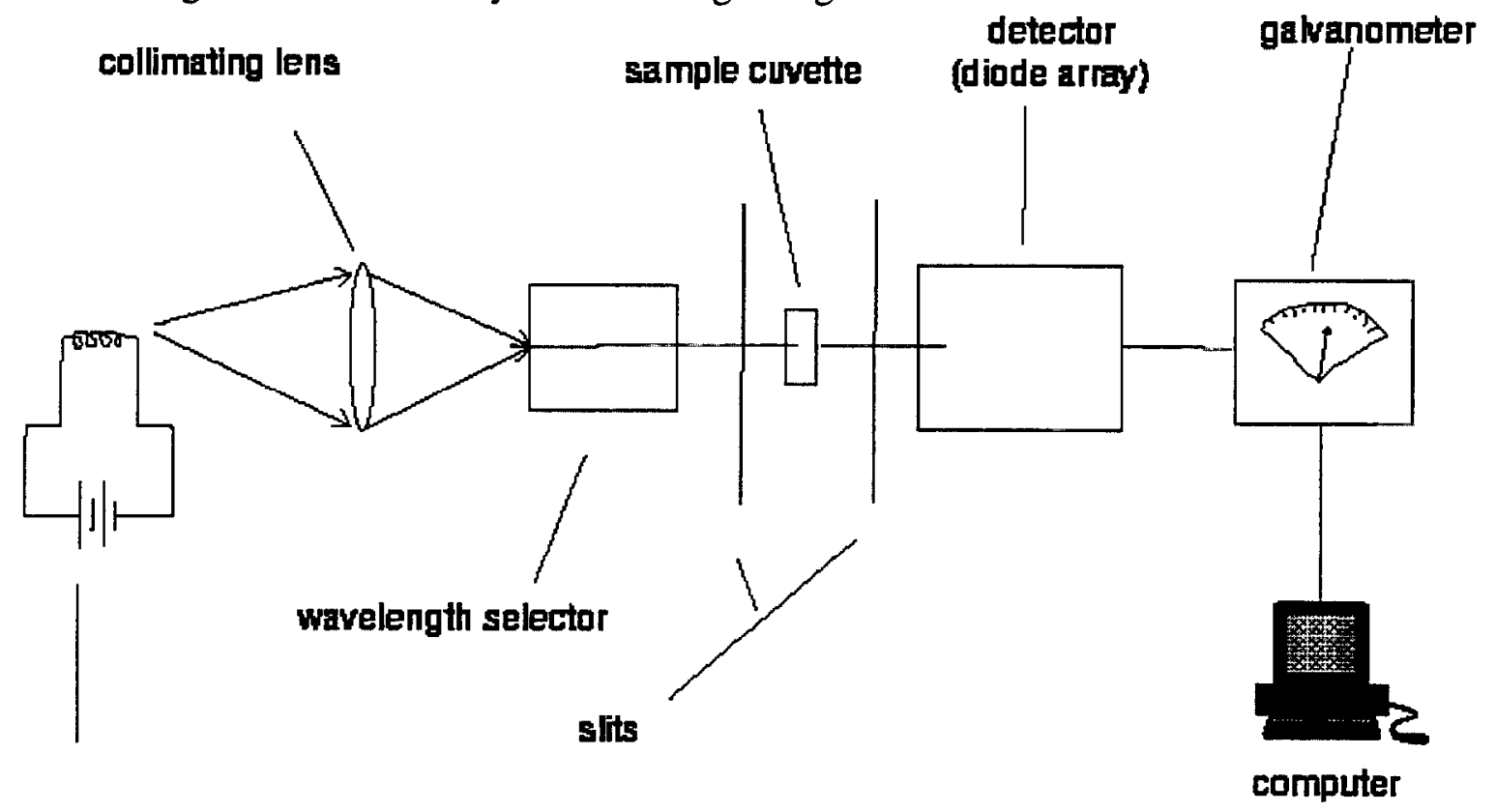

light source

Fig. 3 Schematic of single beam spectrophotometer (Pesce et al., 1971) 
The absorption spectrum of each methanol solution was measured on a diode array UVVis spectrophotometer that had a resolution of $\pm 1 \mathrm{~nm}$. Each lubricant was dissolved in methanol and placed in the sample cuvette for measurement. Before measuring the spectra of the solutions, the absorption spectrum of pure methanol was measured to serve as a control (blank). Methanol shows no absorption beyond the rise approaching $190 \mathrm{~nm}$, corresponding to the $n \Rightarrow \sigma^{*}$ transition. ${ }^{1}$ The intensity maxima of the absorption bands thus measured furnished the $\lambda_{\text {exe }}$ that were later used for fluorescence measurements. These absorption spectra are provided in Appendix A for each lubricant.

\section{Fluorescence}

The fluorescence spectra of the methanol solutions of each lubricant were measured with a scanning spectrofluorimeter. The methanol/lubricant mixtures were contained in a sample cuvette during the fluorescence measurements. Figure 4 shows a simplified schematic of a right angle spectrofluorimeter. The lamp and the lens of the spectrofluorimeter focuses the light into a monochromator. The monochromator is set to emit light at a desired wavelength, i.e., $\lambda_{\text {exe. }}$. The light is directed to the cuvette containing the sample media. Right angle emissions enter the fluorescent monochromator where either the fluorescence spectra remains intact or certain wavelengths may be removed by filtering. The photocell and the galvanometer are used to measure the intensity of the fluorescent light.

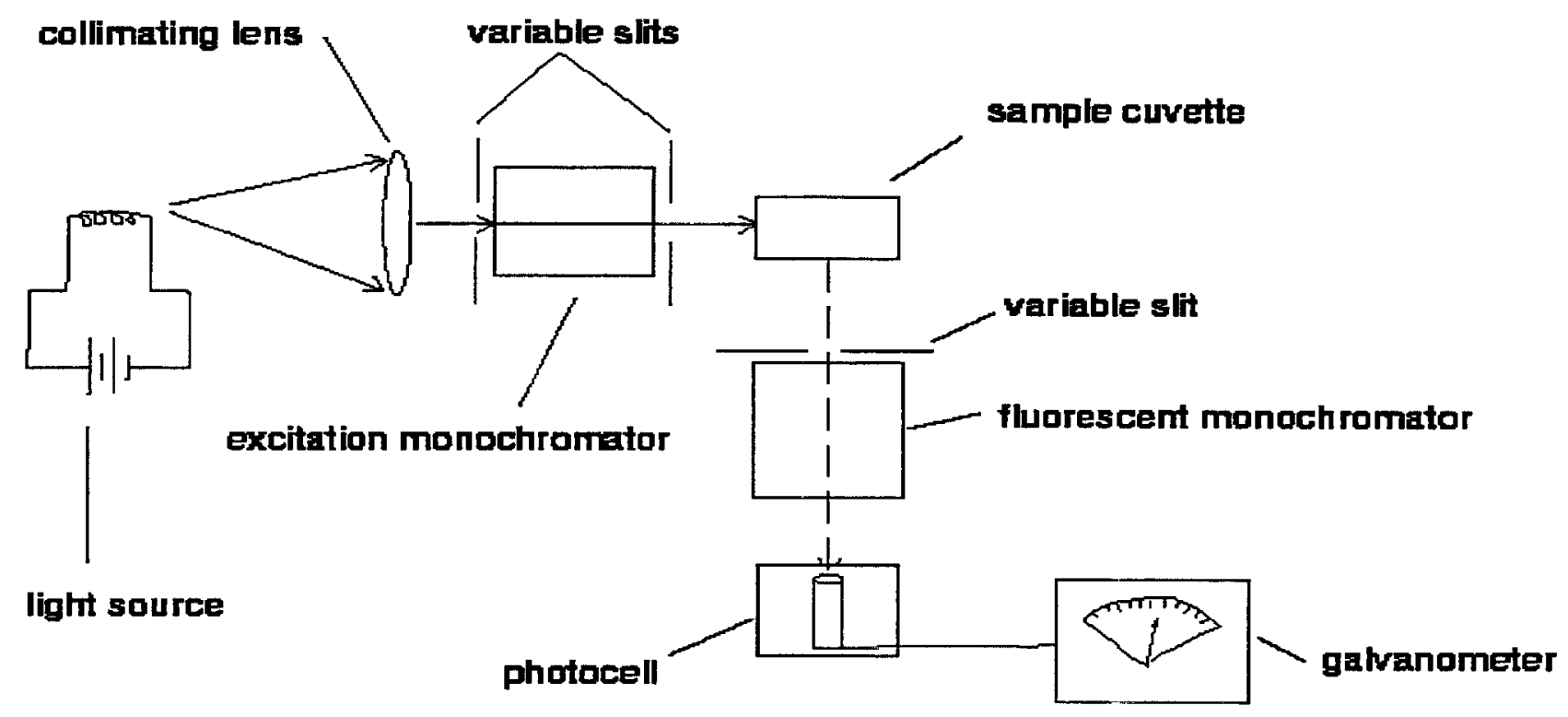

Fig. 4 A right angle spectrofluorometer (Pesce et al., 1971)

'It was initially desired to dissolve the lubricant in a nonpolar, moderately polar, and polar, and polar solvent for spectral measurements to facilitate identification of the transitions responsible for each band. Unfortunately, the samples were insoluble in nonpolar solvents such as decane. In some cases, emulsions were formed that could not be dispersed by ultrasound or any conventional means. All samples except Zerol-300 did dissolve in methanol. 
The expanded measurement uncertainty for the wavelength measurement and the emission intensity measurement were $2 \mathrm{~nm}$, and $0.14 \mathrm{mV}$, respectively. The expanded uncertainty of the emission intensity was estimated with the law of propagation of uncertainty from the measured intensities. The expanded uncertainty of the wavelenght measurement was obtained from the resolution of the instrument. The expanded measurement uncertainties are reported for a 95\% confidence interval and are evaluated by statistical methods.

The cuvette sample solutions were purged with helium for 5 minutes before measuring the spectra to minimize oxygen contamination that can cause fluorescence quenching. In cases where the absorption spectrum shows more than one distinct band, fluorescence spectra were measured for each maxima. The fluorescence spectra are provided in Appendix B for each lubricant.

The fluorescence of the samples is marked by the red shift apparent in each spectrum. In most cases, the fluorescence spectrum resembles the absorption spectrum. While the fluorescence is generally weak to moderate, it is clearly of an intensity level that can be measured with modest uncertainty and used for analytical purposes. Although no spectra was measured for Zero 300 , it is expected that the alkylbenzene material will show fluorescence.

The absorption and fluorescence measurements for the methanol/lubricant samples in the cuvette have shown that the lubricants exhibit useful fluorescence. However, the intensity of the emission from the cuvette was moderate. The intensity of the fluorescence can be increased with a specially designed target to maximize the quantity of lubricant that can emit fluorescence perpendicular to the incident beam and to reflect noxious scattering either away from the detector or back into the sample. The target holds the lubricant in the beam in the absence of solvent.

\section{SPECTRAL MEASUREMENT FROM THE TARGET}

A vignetting target was specifically designed to increase the fluorescence intensity of the sample lubricants. The target was fabricated from 6061 aluminum by wire electric discharge machining (EDM). Figure 5 shows the orientation of the target with respect to the source and detector of the scanning spectrofluorimeter. Figure 5 also shows that the surface of the detector was "stepped." There are 1.31 radians (a $75^{\circ}$ angle) between the "rise" and the "tread" of the steps was intended to direct the light that was reflected from the target away from the detector. The target was tested in the as-machined condition after cleaning with appropriate solvents in a Soxlett extractor. The target was sized to fit within the corner confines of a typical spectrophotometry cuvette. A low-cost plastic cuvette was cut so that the bottom half could accommodate the target securely. The target was then held in the sample compartment in the configuration shown schematically in Fig. 4. 


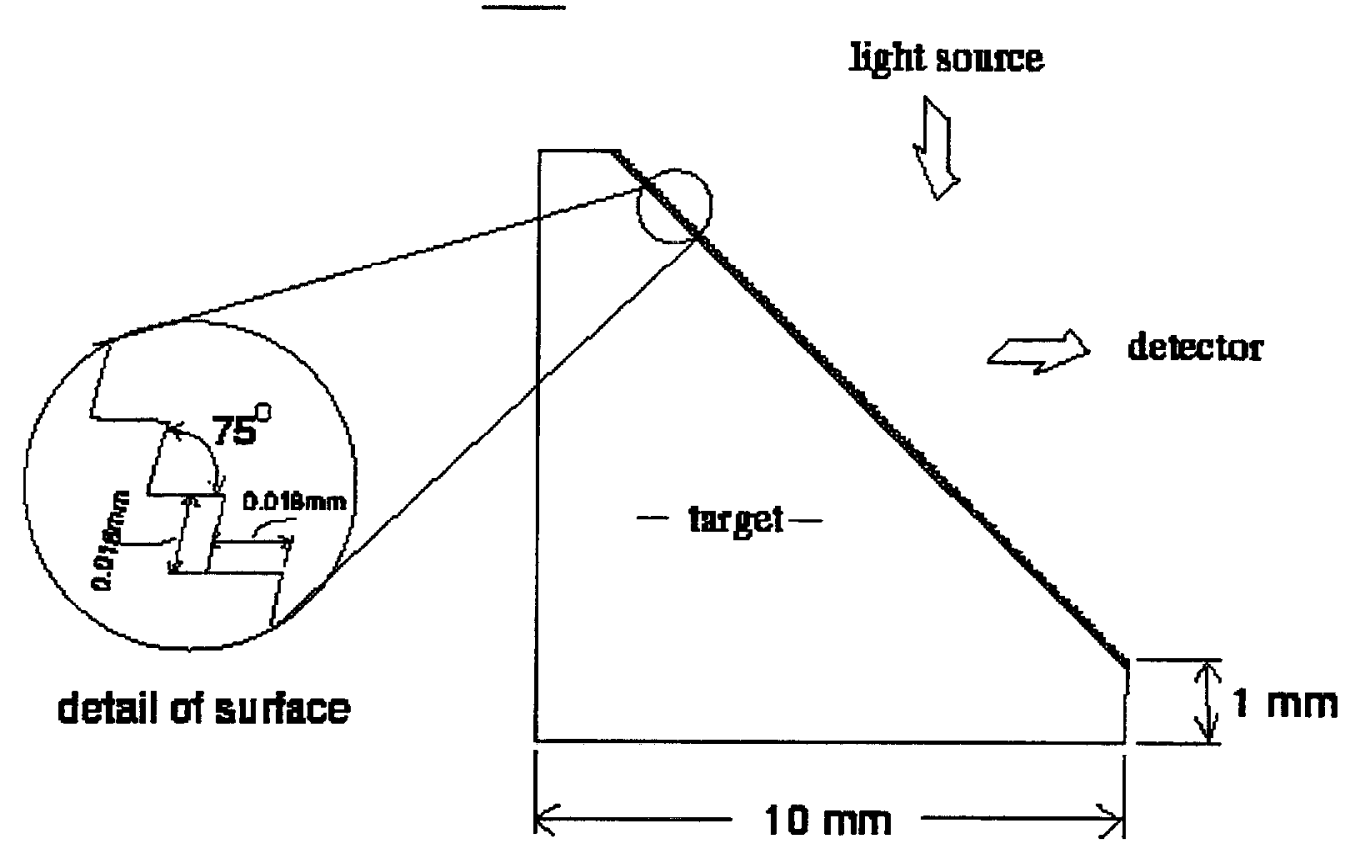

Fig. 5 Aluminum vignetting target for fluorescence detection

The fluorescence spectrum of each lubricant was measured on the target by micropipetting $50 \mu \mathrm{L}$ to $150 \mu \mathrm{L}$ of neat lubricant on the target, and allowing it to spread over the light spot area of the surface. The target was washed thoroughly with methanol in a cuvette washer between samples. For these experiments, no precaution was taken to exclude oxygen because the lubricant was present at a relatively high concentration. Future work should incorporate a nitrogen purge to reduce oxygen quenching.

The spectra plots are presented in Appendix B. Each figure gives two plots of the same spectrum. This first spectrum shows a relatively large scale intensity, while the second is magnified to show fine structure of the intensity. In each case, the blank (taken on the uncoated plate) and the spectrum taken earlier in the methanol solution (Appendix A data) are shown on the graph for comparison. In general, the fluorescence spectra taken on the target, in most cases, show approximately the same fluorescence bands as do the solution spectra. ${ }^{2}$ The wavelengths at which the intensity maxima occur $\left(\lambda_{\text {max }}\right)$ for the methanol solution and the target data are within $50 \mathrm{~nm}$ of each other. These $\lambda_{\text {max }}$ arise from the fluorescence of the test fluid. The intensity of the fluorescence appears to be sufficient for it to be used as a tool for the measurement of the lubricant concentration.

${ }^{2}$ Frequency shifts are expected; however, because of the potential for hydrogen bonding with methanol, the frequency shifts are solvatochromic. 
Although the fluorescence spectrum of the methanol solution and that for the target are consistent, the spectrum from the target exhibits an additional unexpected phenomena that was not seen in the methanol solution spectrum. The spectrum from the target exhibits an additional $\lambda_{\text {max }}$, at much greater intensities, which is not likely to be due to fluorescence. The large intensities at $\lambda_{\max }$ are believed to be harmonics of the excitation wavelength which are amplified by the presence of the lubricant. Notice that the harmonics are present for the blank spectrum, but at a much smaller intensity. Presumably, the lubricant focuses reflected light from the excitation source resulting in an enhanced harmonic amplitude. We are currently investigating the origins of these bonds. The harmonic enhancing characteristic of the lubricant may possibly be used as the basis of an additional, more sensitive measurement technique for the lubricant concentration.

A table at the bottom of each of the Appendix B figures shows the measured values of the fluorescence and reflection intensities. The refractive index of the lubricants are relatively large, having values greater than or equal to 1.44 . It is speculated that the high refractive index of the lubricant plays a role in focusing the harmonic into a rather high intensity. As a preliminary test of this hypothesis, other non-lubricant fluids with high indices of refraction, such as bromoform, were tested and found to possess the same harmonic focusing characteristics as the lubricants (see Fig. B-12 in Appendix B).

\section{MEASUREMENT TECHNIQUE}

As discussed above, either the harmonic band or the fluorescence band could form the basis of a quantitative measurement strategy. As a preliminary test of the measurement technique, mixtures of spectrophotometric grade methanol and the lubricant CAC 100 were applied to the target in three different mass fractions. Two solutions of $1 \%$ and $5 \%$ CAC 100 were prepared in addition to neat CAC 100. Aliquots of $150 \mu \mathrm{L}$ were applied to the optical spot area of the target, and the methanol was allowed to evaporate. This left a thin coating of lubricant on the target; the quantity of which was proportional to the mass fraction in the solution.

Figure 6 shows the measured fluorescence spectrum for each of three different lubricant mass fractions. The spectrum on bottom is the magnified scale. The peak in the middle of each spectrum at a wavelength of approximately $690 \mathrm{~nm}$ is the harmonic. The smaller intensity peaks to either side of the harmonic are the fluorescence bands. The fluorescence bands are present at roughly $408 \mathrm{~nm}$ and $794 \mathrm{~nm}$. 

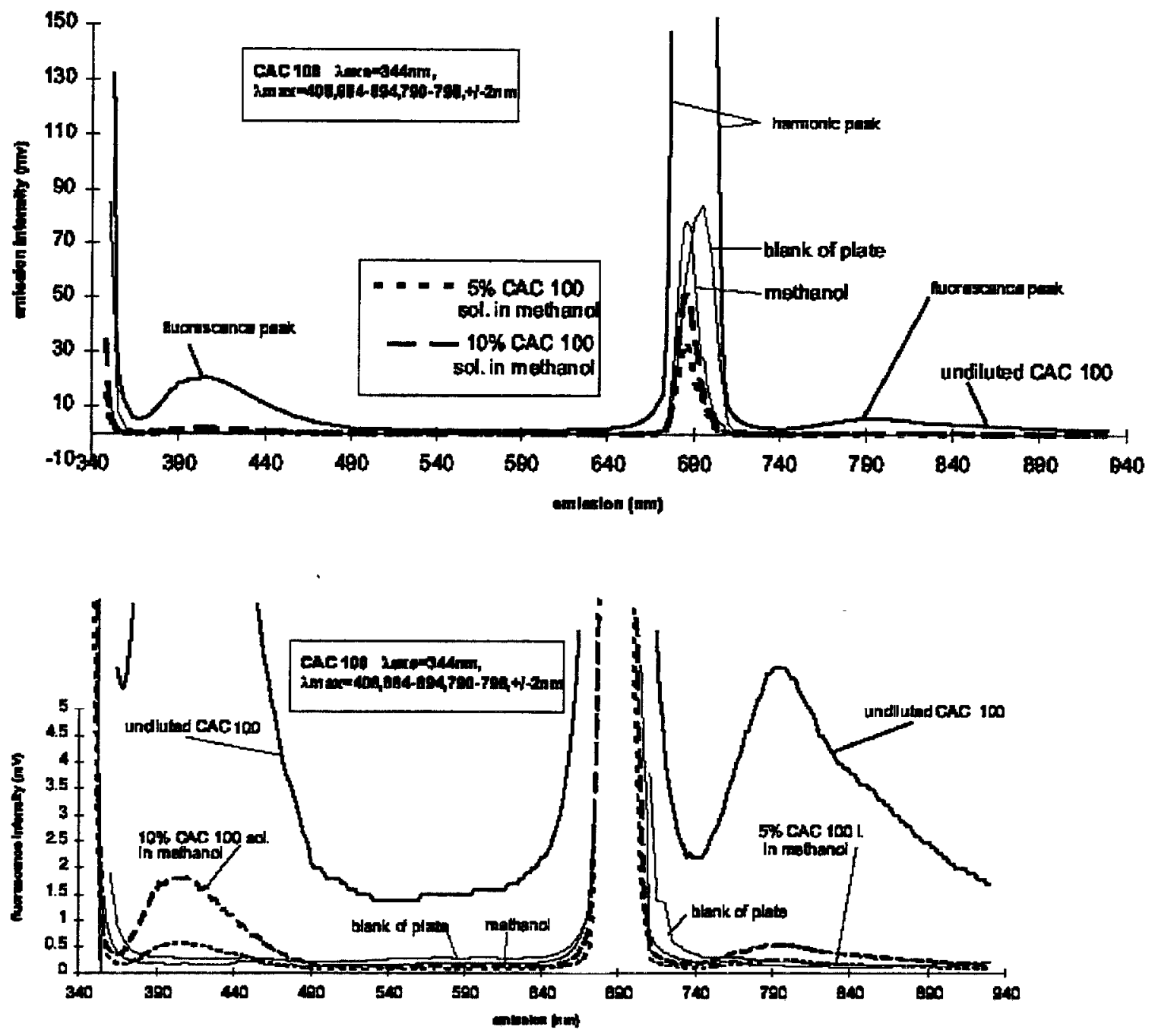

Fig. 6 Effect of mass fraction on fluorescence intensity of CAC 100/methanol mixtures

The measured intensities were regressed (in $\mathrm{mV}$ ) against the mass fraction for each of the three intensity bands. Figures 7 through 9 show the measurements and linear regressions for the three intensity bands. The figures show that the intensity is very linear with mass fraction for all three of the intensity bands. Notice that the magnitude of the harmonic intensity shown in Fig. 9 is much greater than that for either of the fluorescence intensities. More data are required to more completely establish the linear relationship between the intensities and lubricant mass fraction. 
Fluorescence in ten sity vs. concentration of CAC 100 zexe $=344 \mathrm{~nm}$, imax $=408 \mathrm{~nm}$

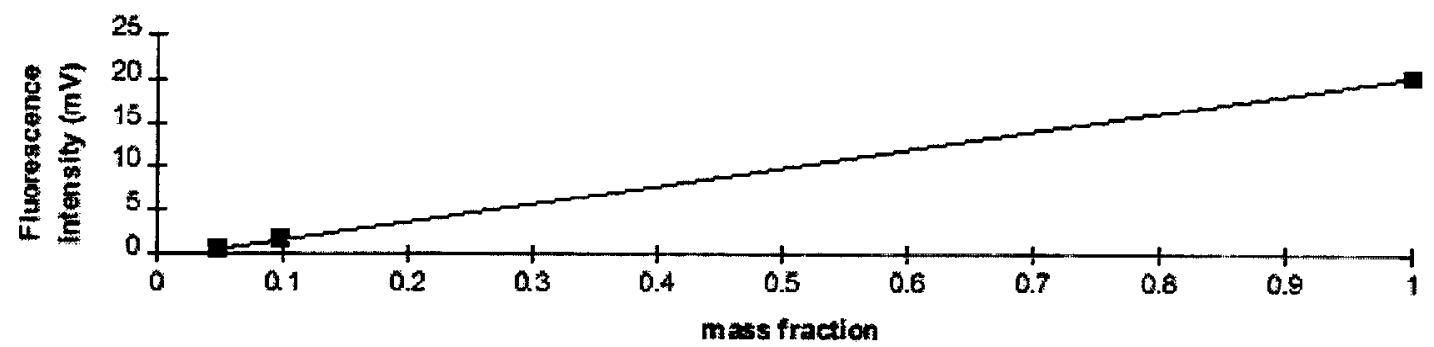

Fig. 7 Fluorescence intensity as a function of mass fraction from the lubricant on the target

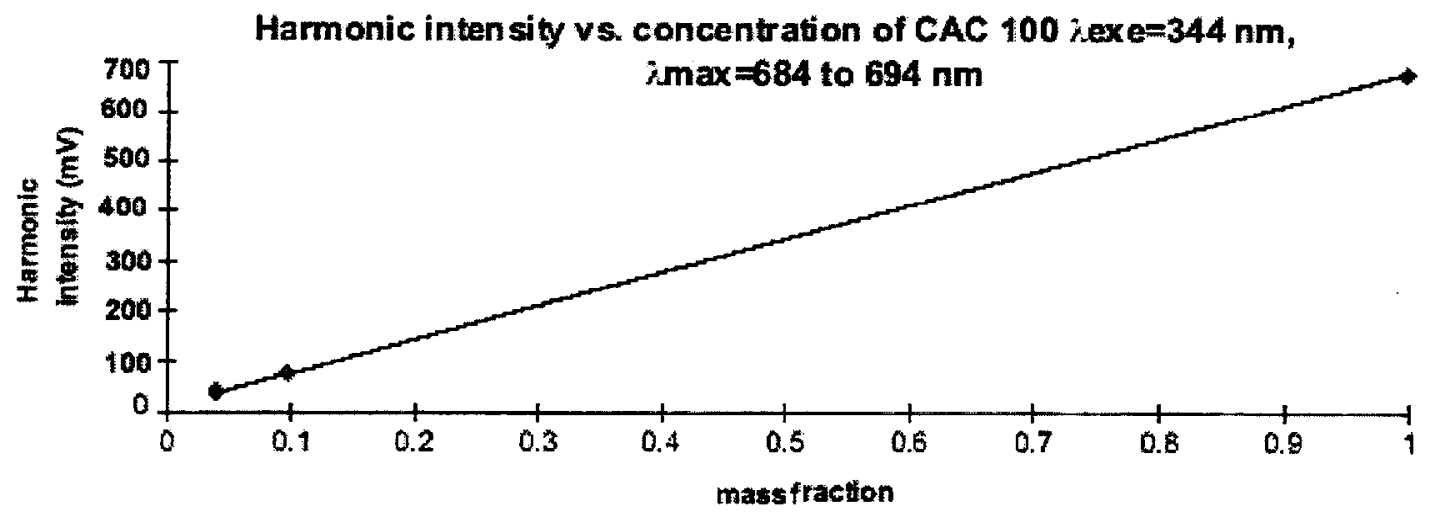

Fig. 8 Intensity of harmonic reflected light from target as a function of mass fraction

Fluorescence intensity vs. concentration of CAC 100 jexe $=344 \mathrm{~nm}$, imax $=790$ to $798 \mathrm{~nm}$

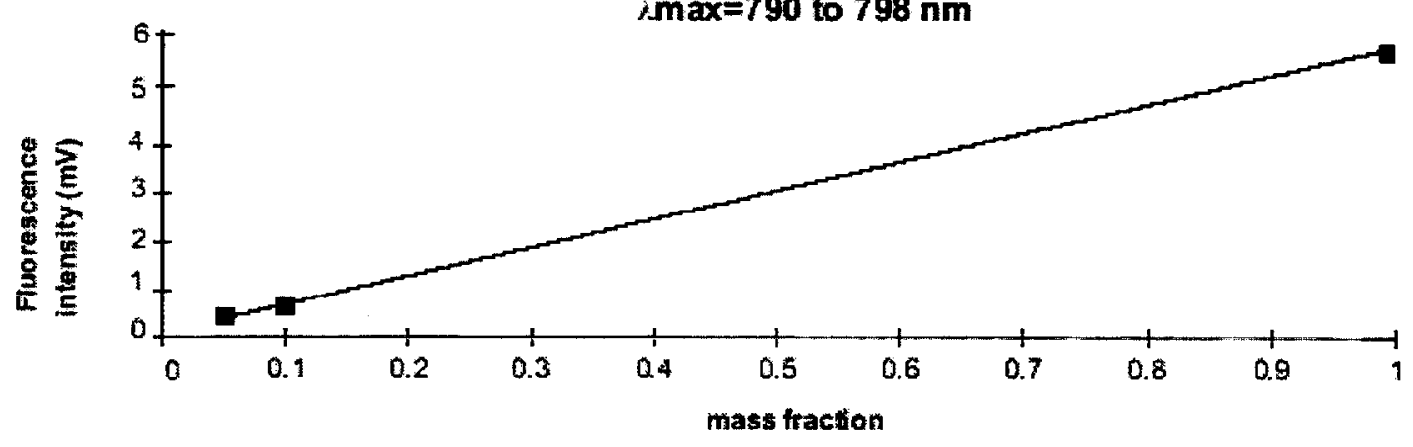

Fig. 9 Fluorescence intensity as a function of mass fraction from the lubricant/methanol mixtures 


\section{APPLICATION OF MEASUREMENT TECHNIQUE}

Existing equipment at NIST will be used to measure the heat flux and the wall superheat of the test fluids while boiling on an enhanced test surface. Figure 10 shows the oxygenfree high-conductivity (OFHC) copper GEWA-T ${ }^{\mathrm{TM}}$ test plate and thermocouple coordinate system to be used in this study. Commercially, the GEWA-T ${ }^{\mathrm{TM}}$ or "T-fin" surface is formed by flattening the tips of a trapezoidal shaped fin. The GEWA-T ${ }^{\mathrm{TM}}$ surface to be tested was machined directly onto the top of the test plate by electric discharge machining (EDM). The gap between the fin-tips is $0.348 \mathrm{~mm}$. The surface has approximately 667 fins per meter oriented along the short axis of the plate. The fin-tip width and the fin-height are $1.05 \mathrm{~mm}$ and $1.038 \mathrm{~mm}$, respectively. It is possible to test other plates including one with a surface identical to that of the fluorescence target.

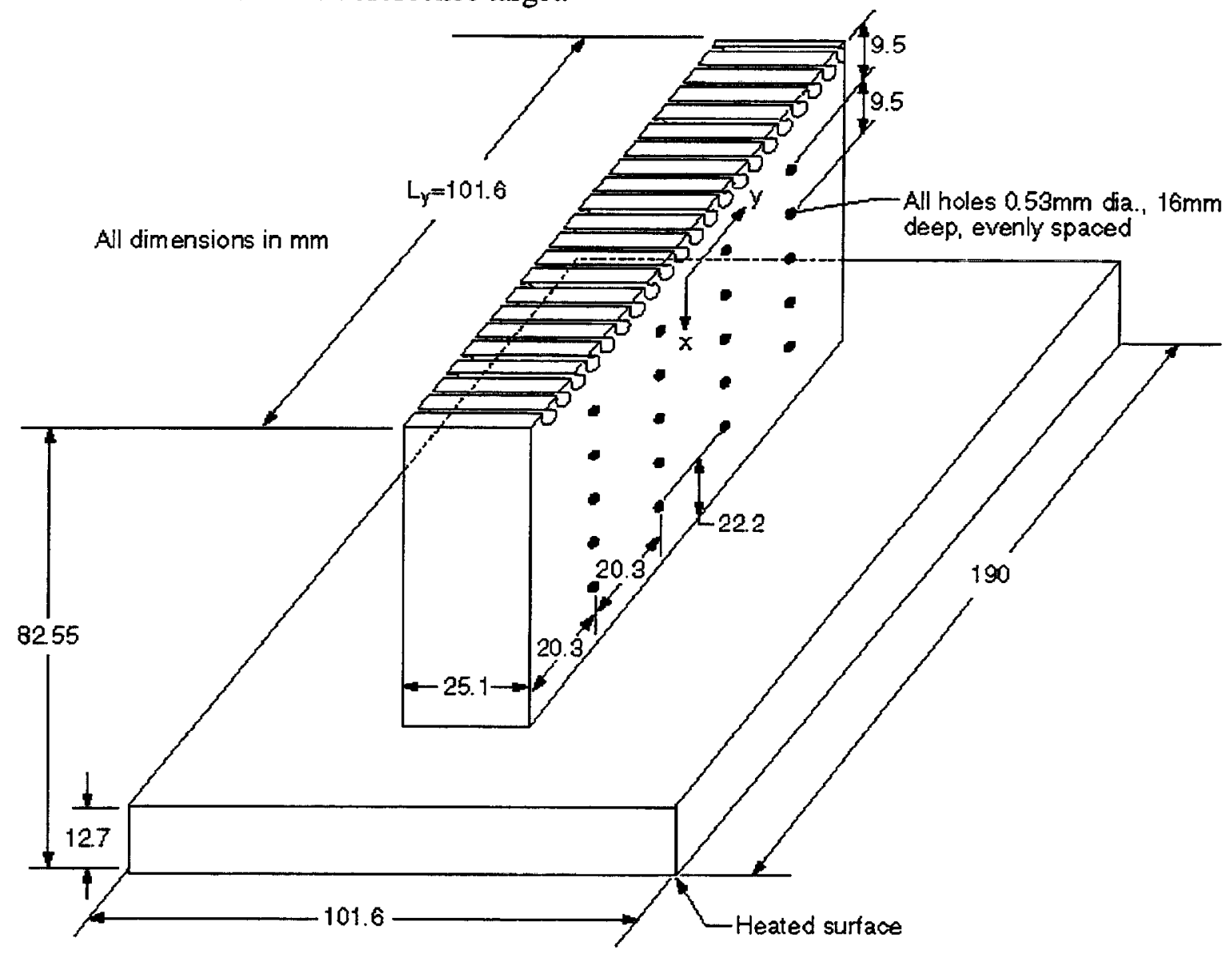

Fig. 10 OFHC copper GEWA-T test plate and thermocouple coordinate system

\section{APPARATUS}

Figure 11 shows a schematic of the apparatus proposed to be used to measure the pool boiling data. The apparatus is used to measure the liquid saturation temperature $\left(T_{s}\right)$, the average pool-boiling heat flux $\left(q^{\prime \prime}\right)$, and the wall temperature $\left(\mathrm{T}_{\mathrm{w}}\right)$. The three principal components of the apparatus are as follows: test chamber, condenser, and reservoir. The internal dimensions of the test chamber are $25.4 \mathrm{~mm} \mathrm{X} 257 \mathrm{~mm} \mathrm{X} 1.54 \mathrm{~m}$. The test chamber is charged with approximately $7 \mathrm{~kg}$ of refrigerant from the reservoir, giving a liquid height of approximately $80 \mathrm{~mm}$ above the test surface. The bottom of the test 
section, as shown in Fig. 11, is heated with high velocity $(2.5 \mathrm{~m} / \mathrm{s})$ water flow. The vapor produced by liquid boiling on the test surface is condensed by the brine-cooled, shell-andtube condenser and returned as liquid to the pool by gravity.

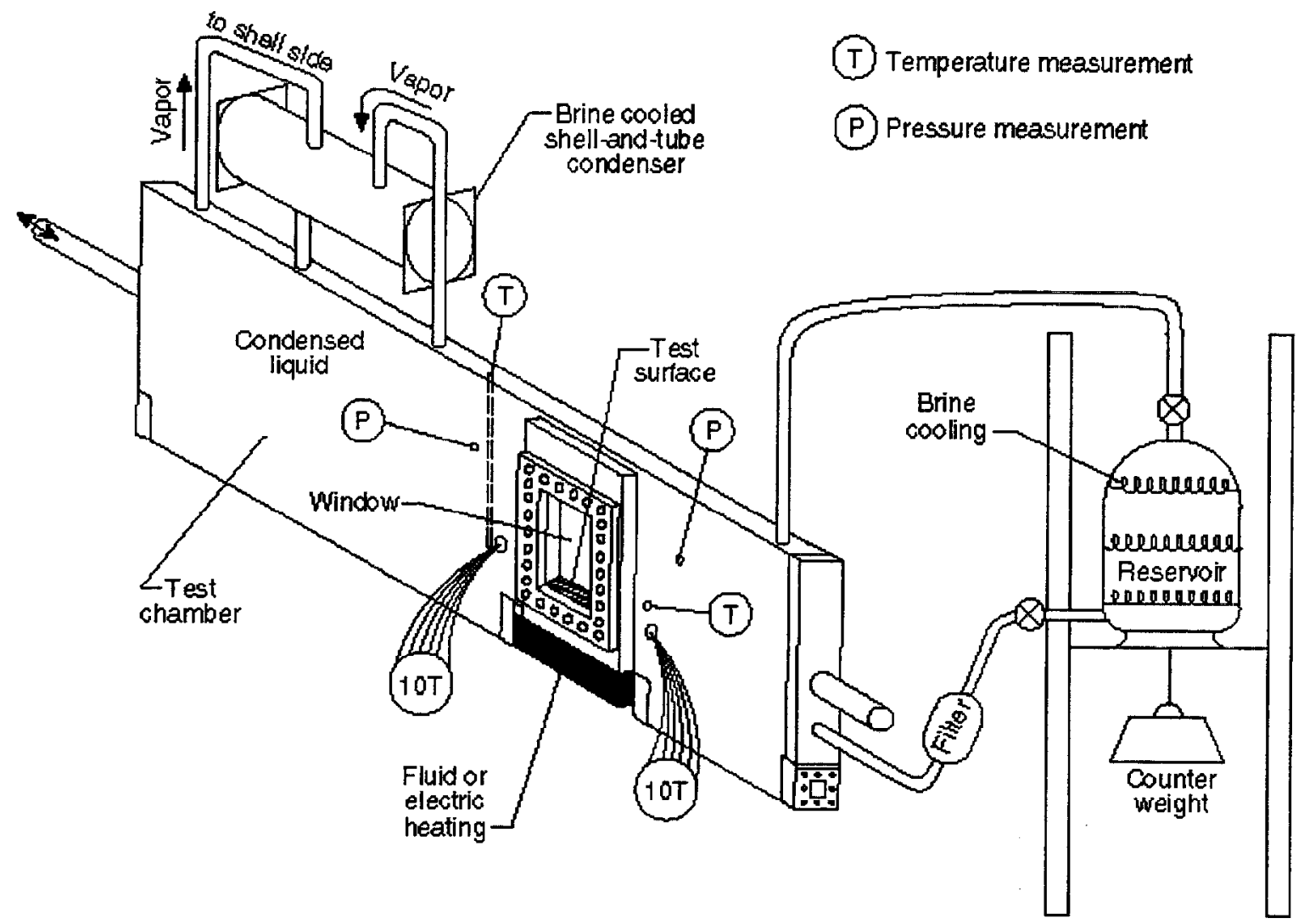

Fig. 11 Schematic of test apparatus

The heat flux and the wall temperature are obtained by regressing the measured temperature distribution of the block to the governing conduction equation. In other words, rather than using the boundary conditions to solve for the interior temperatures, the interior temperatures are used to solve for the boundary conditions following a procedure given in Kedzierski (1995).

As shown in Fig. 11, the test section is visible through two opposing, flat $150 \mathrm{~mm} \times 200$ $\mathrm{mm}$ quartz windows. A high-speed camera is used to film the boiling at 1000,3000 , and 6000 frames per second (fps). Two $500 \mathrm{~W}$ forward lights illuminated the specimens during filming. Films are taken at selected heat fluxes immediately after the measurement of the heat-transfer coefficient to ensure that the heat from the lights did not influence the measurement.

Figure 12 shows the test section instrumented with a bifurcated optical bundle. The optical bundle is housed in a $9.5 \mathrm{~mm}$ diameter, $355 \mathrm{~mm}$ long quartz tube to isolate it from the test fluid. The quartz tube is sealed at the top of the test chamber with a Teflon seal fitting. The 
bifurcated optical bundle contains both the excitation and emissions detection in the single cable. The fluorescence is measured with a spectrofluorometer that was modified to accept the bifurcated optical bundle. The excitation can be focused to a single point above the heat transfer surface. Theoretically, a concentration distribution could be measured by traversing the optical bundle in a direction that is perpendicular to the heat transfer surface. The maximum concentration is found at the peak emission intensity. The focal length of the bundle will determine the distance between the probe and the heat transfer surface.

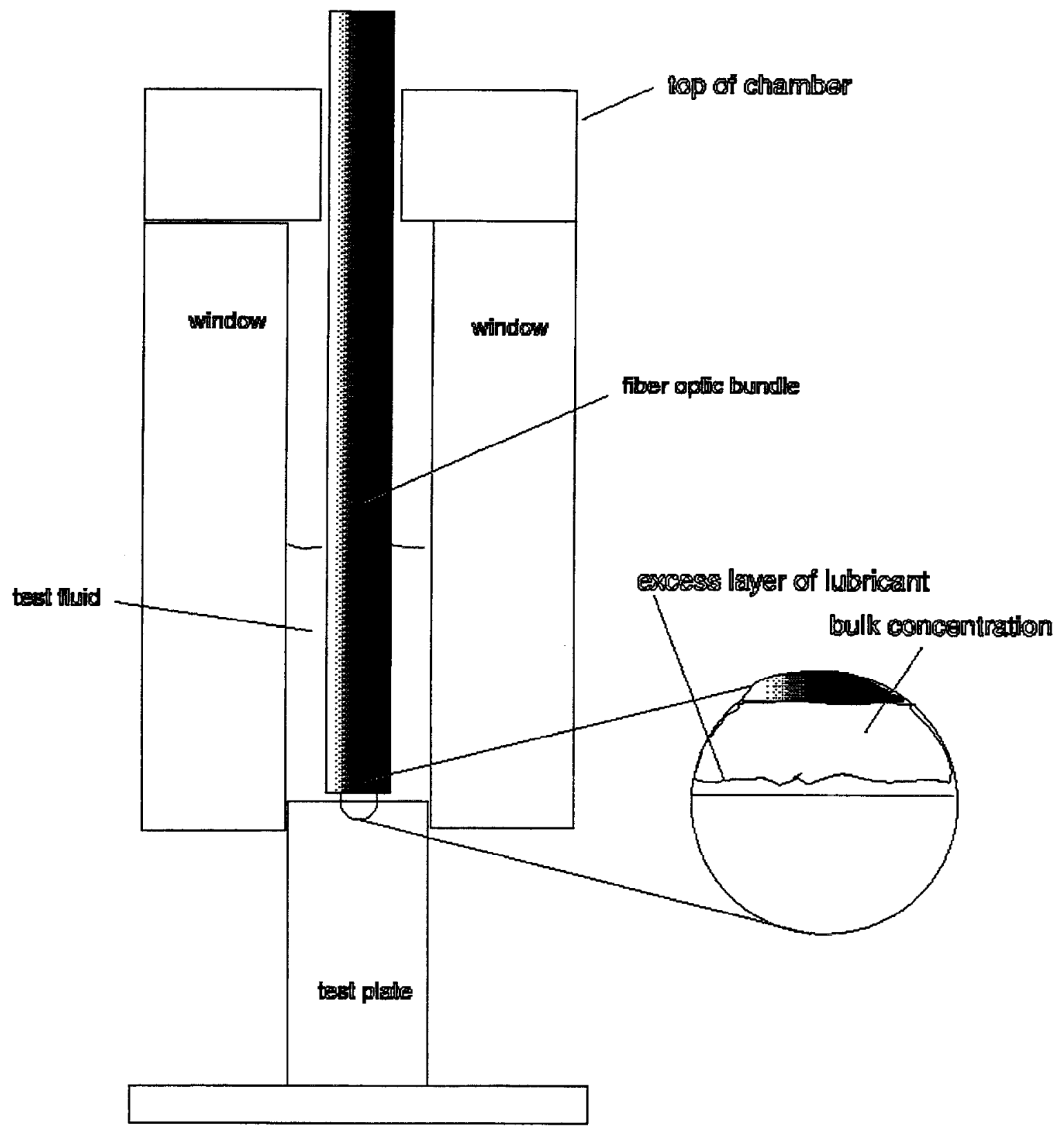

Fig. 12 Test section with bifurcated optical bundle 
Calibration of the test system shown in Fig. 12 can be done insitu by removing the windows and placing known concentrations of methanol/lubricant solutions on the test surface. The procedure for this can be the same that was used to produce Figs. 7 through 9. The intensity fit with the smallest uncertainties will be used for the boiling measurements.

It may not be possible to make the optical measurements while boiling occurs on the heat transfer surface. The boiling may produce erratic scattering of both the excitation and emission. In this event, boiling will commence until a steady heat transfer is reached. Steady state conditions indicate that an equilibrium between deposition and removal of the excess lubricant layer has been reached. Once steady state has been reached, the boiling will be quenched to permit the optical measurements. The measurements will be made immediately after quenching. In this way, not much of the lubricant excess layer will have diffused back into the bulk liquid.

\section{CONCLUSIONS}

The initial steps have been completed to demonstrate the viability of using the fluorescence and reflected harmonic measured from a target as the basis for a lubricant concentration measurement technique. Several commercial lubricants were found to have significant florescent and harmonic focusing properties. The florescent intensity from a target with lubricant was shown to be linear with respect to lubricant mass fraction. The harmonic focusing property of the lubricant was an unexpected phenomena. The harmonics are reflections of the excitation wavelength which present for both a clean target and a target with lubricant. However, the harmonic intensities are much greater for the targets with lubricants. This intensity was found to linearly increase with lubricant mass fraction. Presumably, the lubricant focuses reflected light from the excitation source resulting in an enhanced harmonic amplitude. It was proposed that either the fluorescence or the reflected harmonic measured from a boiling heat transfer surface could be used to obtain the mass fraction of lubricant on the surface. More extensive work is required to confirm the linear relationship between intensity and lubricant mass fraction.

It was proposed to modify an existing pool boiling test rig by including a bifurcated optical bundle to measure the intensities from the heat transfer surface. The bifurcated optical bundle contains both the excitation and emissions detection in the single cable. The fluorescence is measured with a spectrofluorometer that was modified to accept the bifurcated optical bundle. The excitation can be focused to a single point above the heat transfer surface. Theoretically, a mass fraction distribution could be measured by traversing the optical bundle in a direction perpendicular to the heat transfer surface.

\section{ACKNOWLEDEMENTS}

This work was jointly funded by NIST, and the U.S. Department of Energy (project no. DEAI01-91CE23808) under Project Manager Esher Kweller. The authors thank the following NIST personnel for their constructive criticism of the first draft of the manuscript: Dr. Vance Payne, Dr. James Schmidt, and Mrs. Janet Land. All of the absorption and fluorescence measurements were performed at NIST, Boulder. The concept for the 
vignetting target and the harmonic measurement technique was also developed at NIST, Boulder.

\section{REFERENCES}

Adamson, A. W., 1967, Physical Chemistry of Surfaces, Interscience Publ., New York, 2nd Ed., p. 353.

Carey, V. P., 1992, Liquid-Vapor Phase-Change Phenomena, Hemisphere, Washington.

Eckert, E. R. G., and Goldstein, R. J., 1976, Measurements in Heat Transfer, Hemisphere, Washington, 2nd ed., pp. 9-11.

Hsu, Y. Y., 1962, "On the Size Range of Active Nucleation Cavities on a Heating Surface," J. Heat Transfer, Vol. 84, pp. 207-216.

Jontz, P. D., and Myers, J. E., 1960, "The Effect of Dynamic Surface Tension on Nucleate Boiling Coefficients," AICHE Journal, Vol. 6, No. 1. pp. 34-38.

Kedzierski, M. A., 1996, "Enhancement of R123 Pool Boiling by the Addition of NHexane," NISTIR 5780, U.S. Department of Commerce, Washington, D.C.

Kedzierski, M. A., 1995, "Calorimetric and Visual Measurements of R123 Pool Boiling on Four Enhanced Surfaces," NISTIR 5732, U.S. Department of Commerce, Washington.

Kedzierski, M. A., 1993, "Simultaneous Visual and Calorimetric Measurements of R11, R123, and R123/Alkylbenzene Nucleate Flow Boiling," in Heat Transfer with Alternative Refrigerants, HTD-Vol. 243, H.J. Sauer, Jr., and T.H. Kuehn, Eds., ASME, New York, pp. 27-33.

Kedzierski, M. A., and Kaul, M. P., 1993, "Horizontal Nucleate Flow Boiling Heat Transfer Coefficient Measurements and Visual Observations for R12, R134a, and R134a/ Ester Lubricant Mixtures," The 6th International Symposium on Transport Phenomena in Thermal Engineering, Seoul, Korea, Vol. 1, pp. 111-116.

Kedzierski, M. A., and Worthington, J. L. III, 1993, "Design and Machining of Copper Specimens with Micro Holes for Accurate Heat Transfer Measurements," Experimental Heat Transfer, vol. 6. pp. 329-344.

Lunger, B. S., and Shealy, G. S., 1994, "Compositions of a Hydrofluorocarbon and a Lubricant," International Patent WO 94/18282.

Pesce, A. J., Rosen, C.-G., Pasby, T. L., 1971, Fluorescence Spectroscopy, Marcel Dekker Inc., New York, p. 151.

Rosen, M. J., Surfactants and Interfacial Phenomena, John Wiley \& Sons, New York, p.57. 
Shah, B. H., and Darby, R., 1973, "The Effect of Surfactant on Evaporative Heat Transfer in Vertical Film Flow," Int. J. Heat Mass Transfer, Vol. 16, pp. 1889-1903.

Siu, M. C. I., Carroll, W. L., and Watson, T. W., 1976, "Thermal Conductivity and Electrical Resistivity of Six Copper-Base Alloys," NBSIR 76-1003, U.S. Department of Commerce, Washington.

Wu, W., Yang, Y., and Maa, J., 1995, "Enhancement of Nucleate Boiling Heat Transfer and Depression of Surface Tension by Surfactant Additives," J. Heat Transfer, Vol. 117,pp. 526-529. 
APPENDIX A

Absorption Spectra 
APPENDIX A

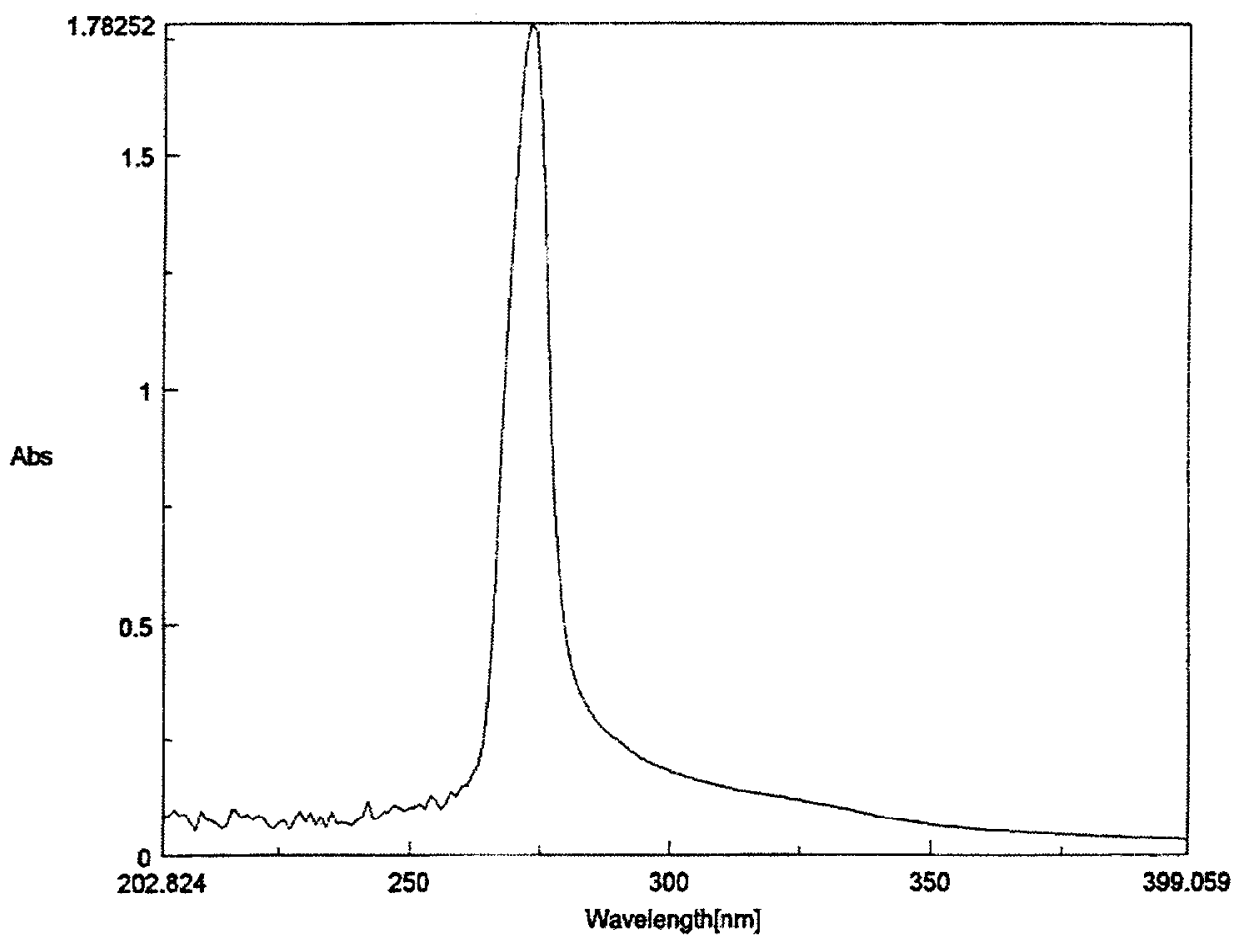

Fig. A - 1 Absorption of Emkarate 203B peak $1 @ 273 \mathrm{~nm}$ absorbance $=1.7965$ 


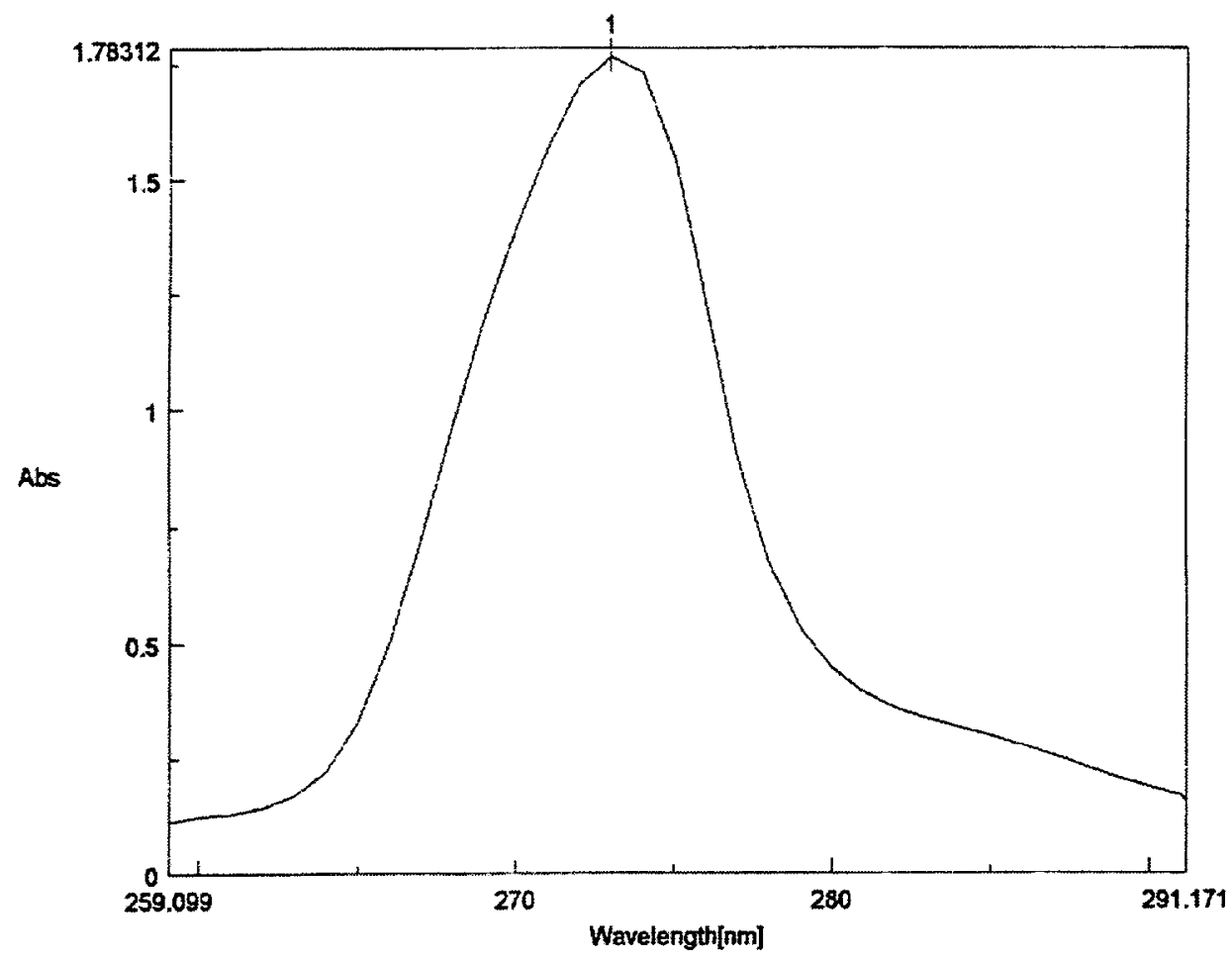

Fig. A - 2 Absorption of Emkarate DE 244B peak 1 @ 273.00nm absorbance $=1.7669$ 


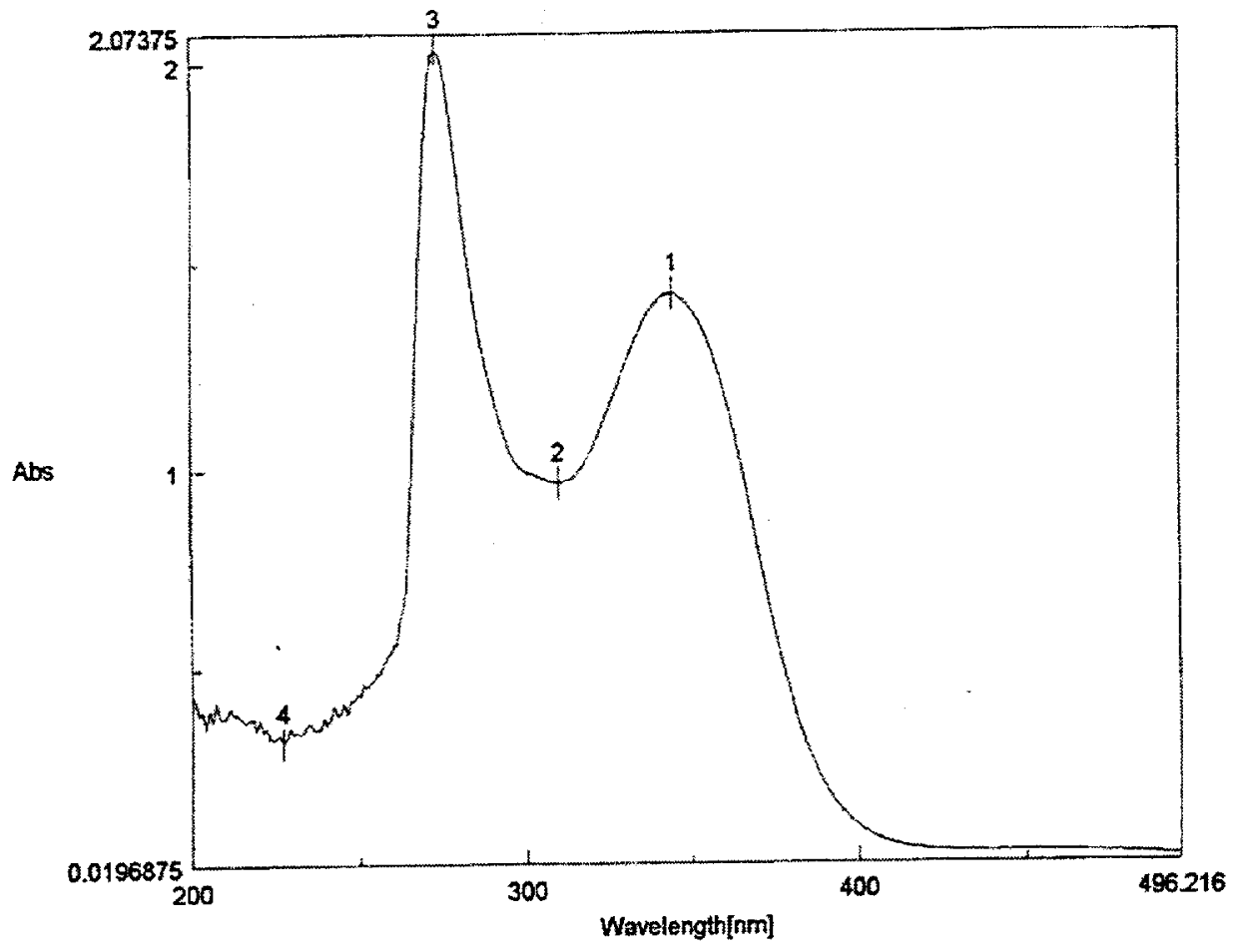

Fig. A - 3 Adsorption of castrol air cool auto 100 peak $1 @ 344.00 \mathrm{~nm}$ absorbance $=$ 1.4269 peak $3 @ 273.00 \mathrm{~nm}$ absorbance $=2.0369$ 


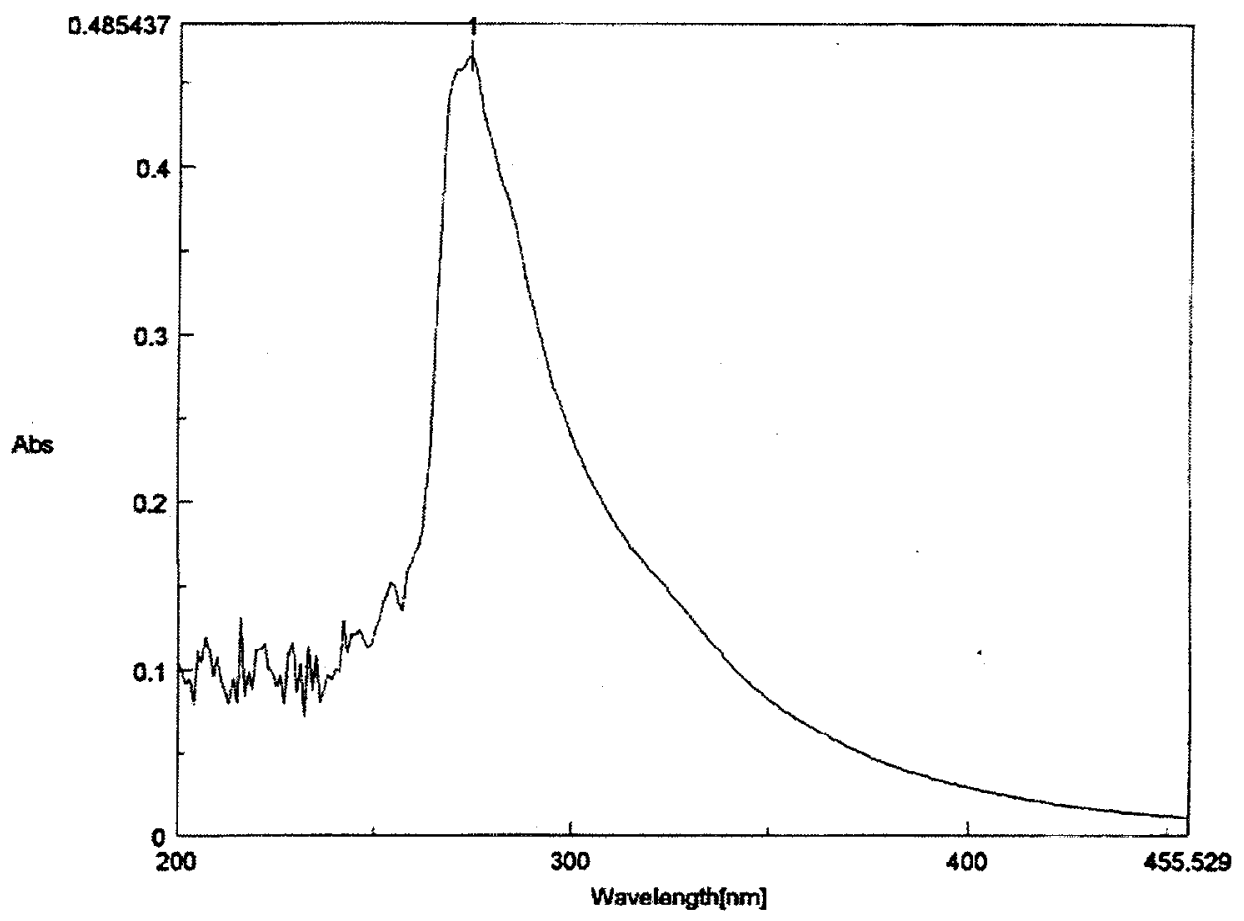

Fig. A - 4 Adsorption for Emkarate 589 peak $1 @ 274.00 \mathrm{~nm}$ absorbance $=0.4662$ 


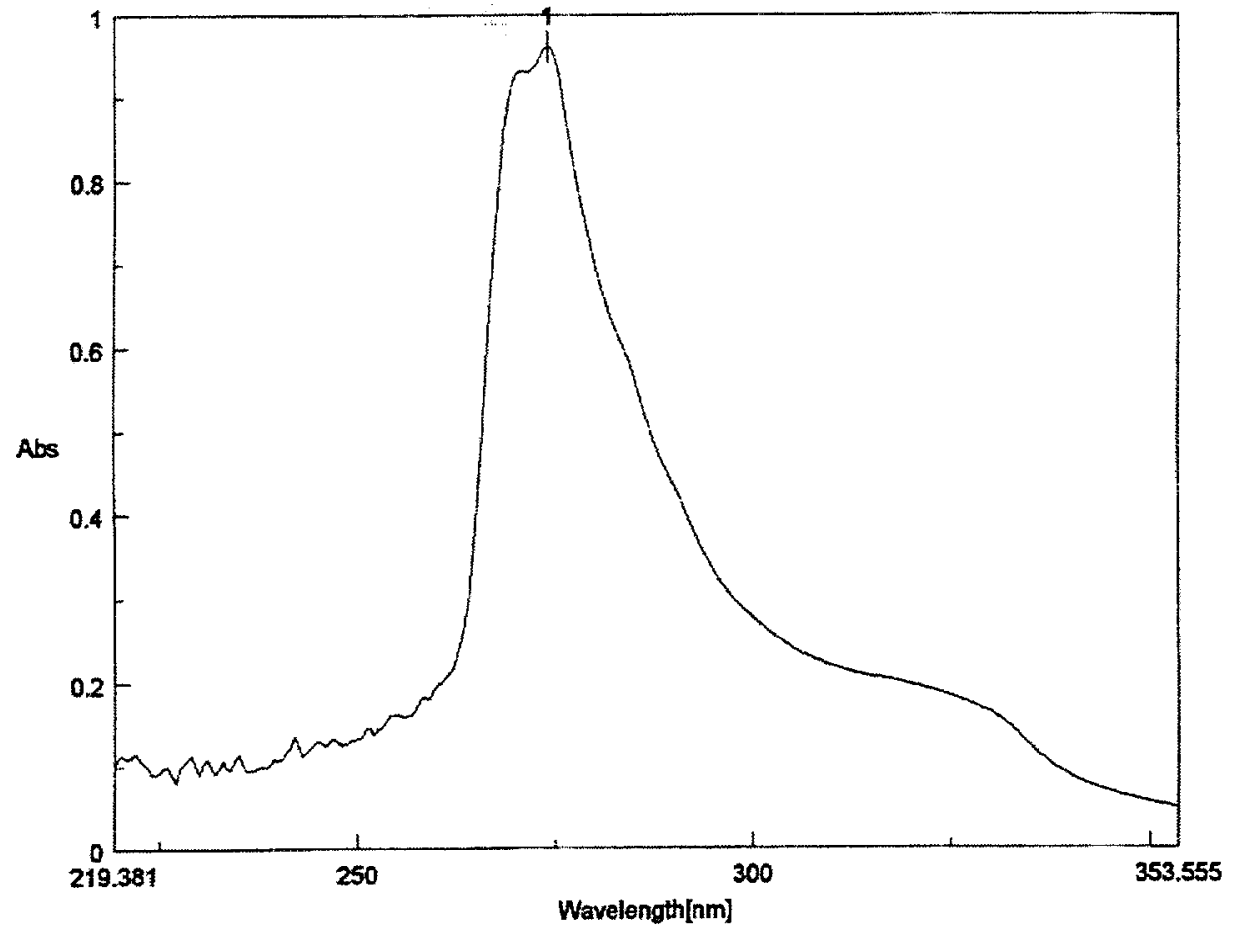

Fig. A - 5 Adsorption for Emkarate 599 peak $1 @ 274.00$ absorbance $=0.9625$ 


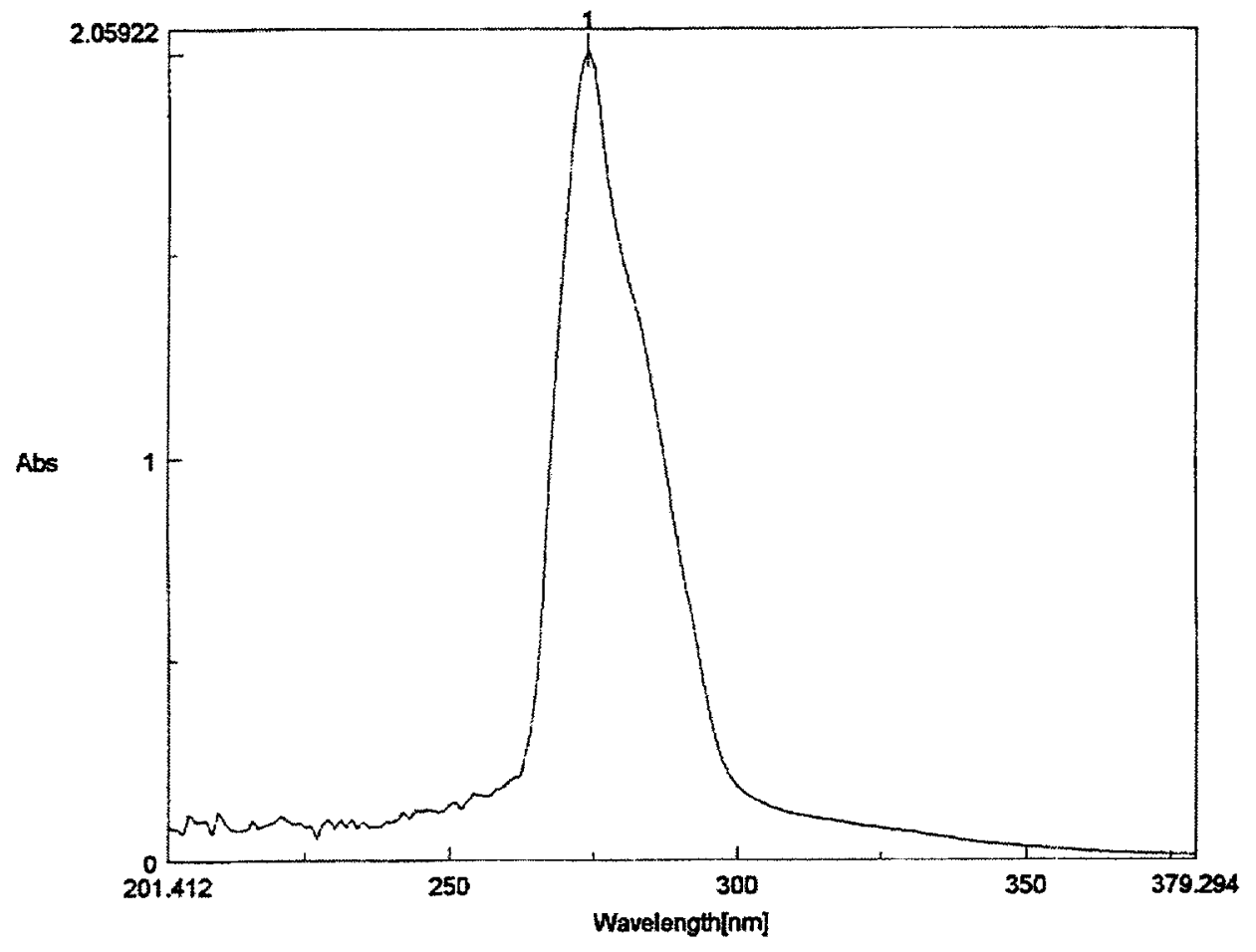

Fig. A - 6 Adsorption for Emkarox DGLF 118 peak $1 @ 274.00$ absorbance $=2.0087$ 


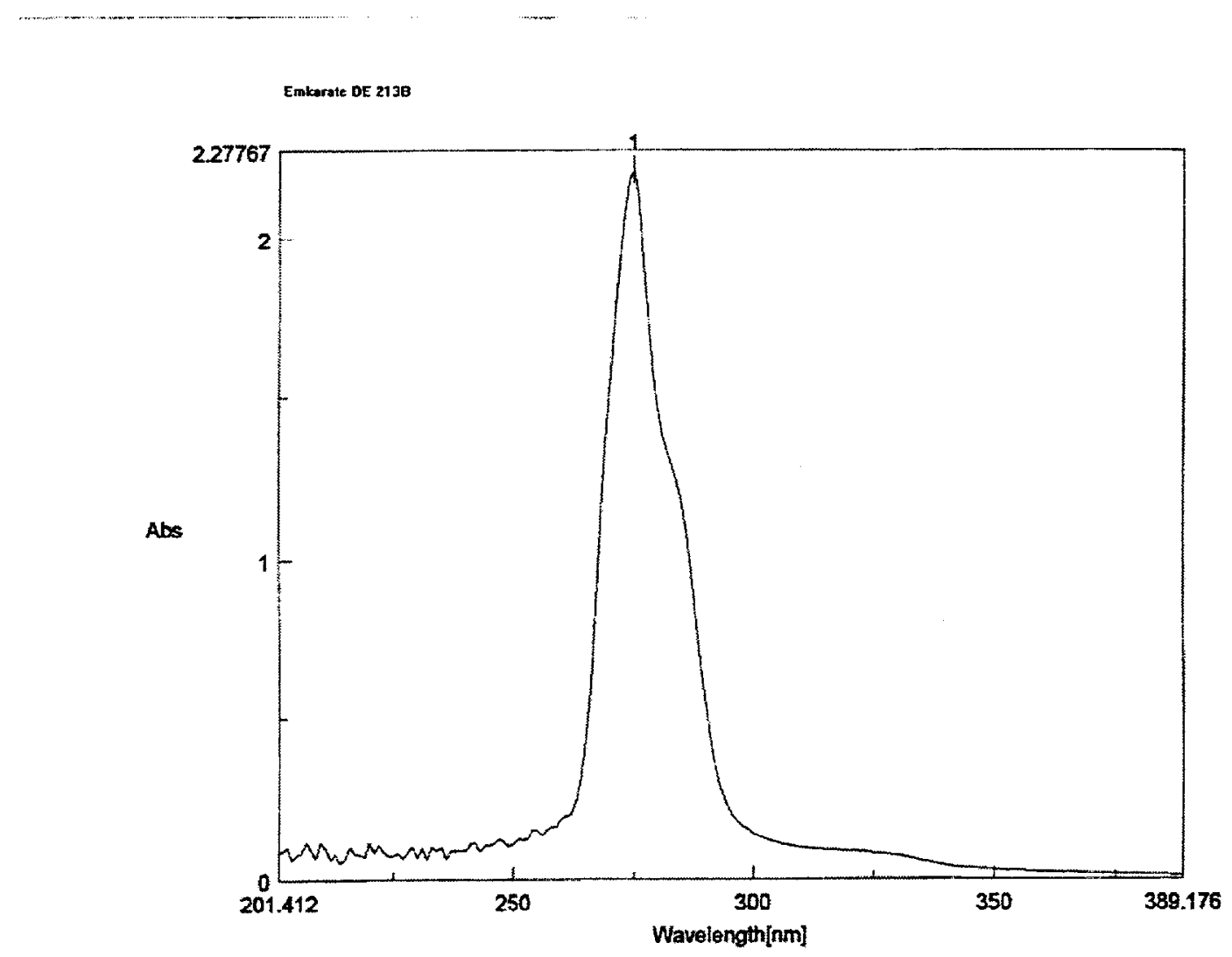

Fig. A - 7 Adsorption for Emkarate DE 213B peak 1 @ 275.00nm absorbance $=2.2187$ 


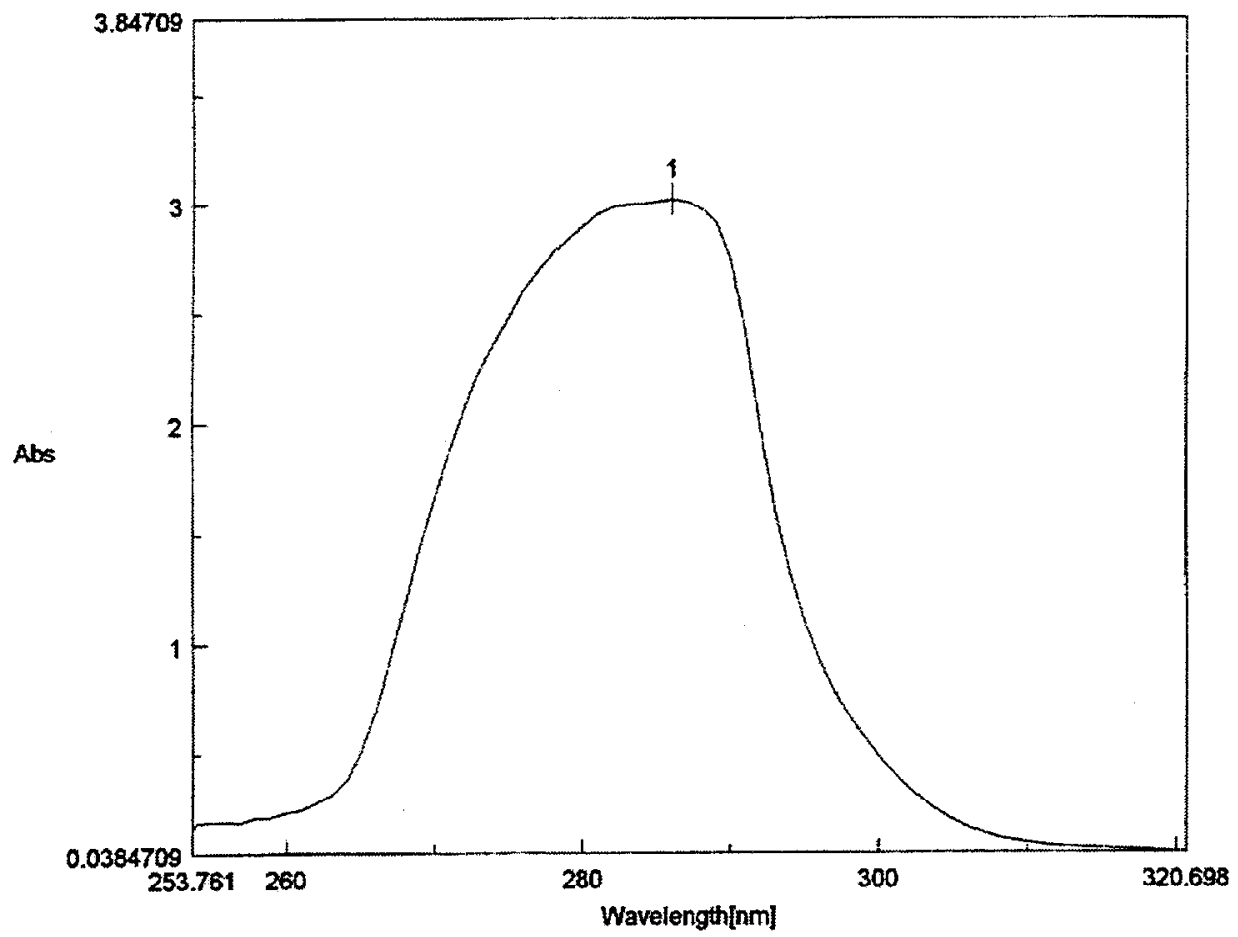

Fig. A - 8 Adsorption for UCON standard refrigerant lubricant 68 peak $1 @ 286.00 \mathrm{~nm}$ absorbance $=3.0243$ 


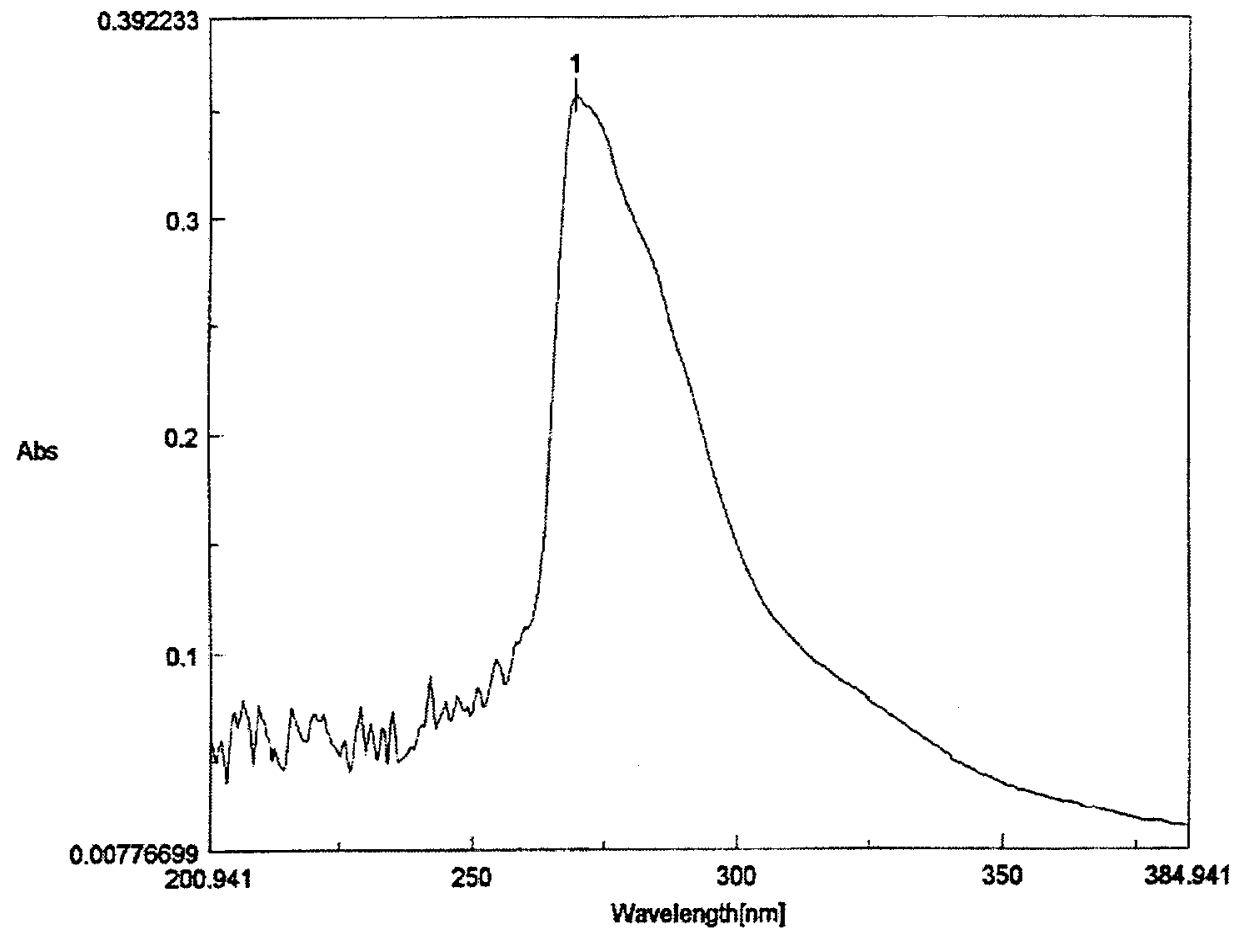

Fig. A - 9 Adsorption for Emkarate DE 601 peak $1 @ 269.00$ nm absorbance $=0.3569$

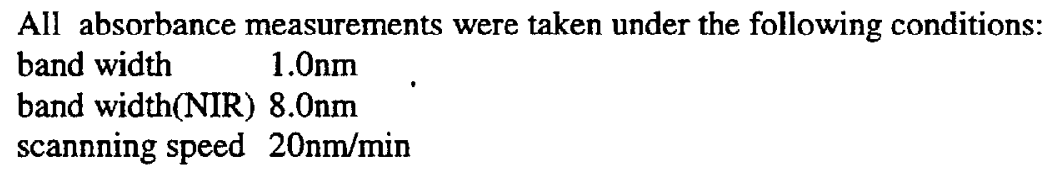




\section{APPENDIX B}

\section{Emission Intensity Spectra}




\section{APPENDIX B}

\section{Lubricant $68 \lambda$ exe $=284 \mathrm{~nm}, \lambda \max =564+/-2,848+/-2 \mathrm{~nm}$}

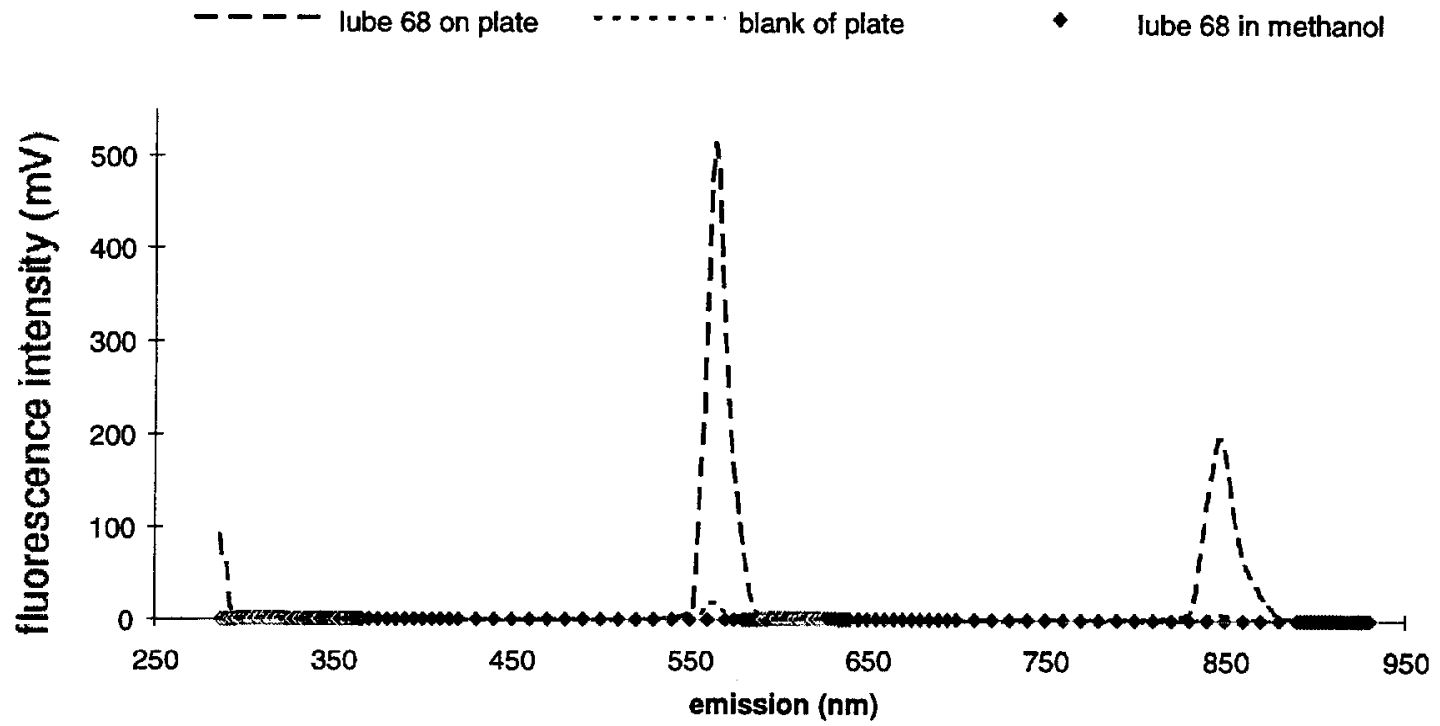

\begin{tabular}{|c|c|c|c|c|}
\hline $\mathrm{nD}$ & \multicolumn{2}{|c|}{ methanol } & \multicolumn{2}{c|}{ plate } \\
\hline 1.1194 & $\begin{array}{c}\lambda \max \quad( \\
+/-1 \mathrm{~nm})\end{array}$ & $\begin{array}{c}\text { fluorescence } \\
\text { intensity (mV) }\end{array}$ & $\begin{array}{c}\lambda \max \\
(+/-2 \mathrm{n} \\
\mathrm{m})\end{array}$ & $\begin{array}{c}\text { fluorescence } \\
\text { intensity } \\
(\mathrm{mV})\end{array}$ \\
\hline & $304 / 305$ & 1.4 & 848 & 198 \\
\hline & $360-362$ & 0.67 & 564 & 514 \\
\hline & 611 & 1.28 & & \\
\hline
\end{tabular}

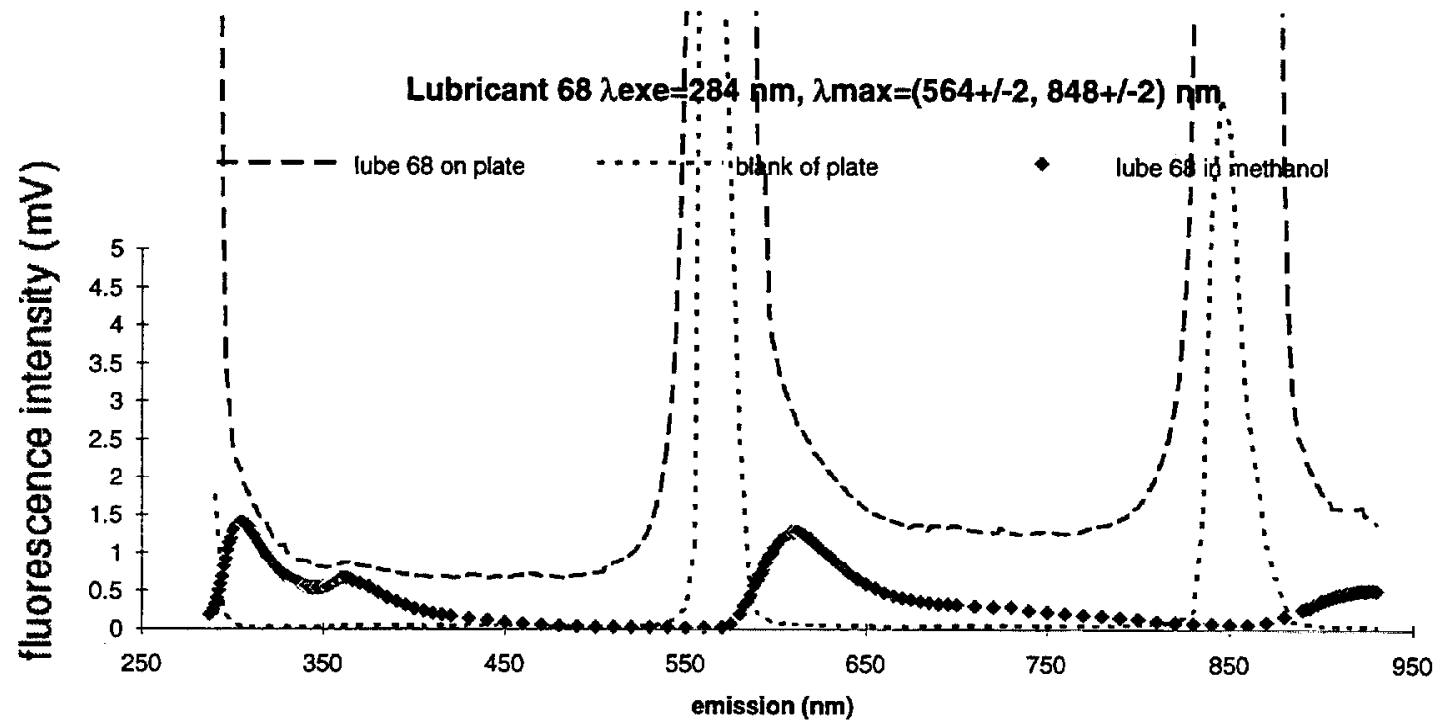

Fig. B - 1 Emission intensity for lubricant 68 
Lubricant De 203b, $\lambda$ exe $=273 \mathrm{~nm}, \lambda \mathrm{max}=550+/-2 \mathrm{~nm}$

竞
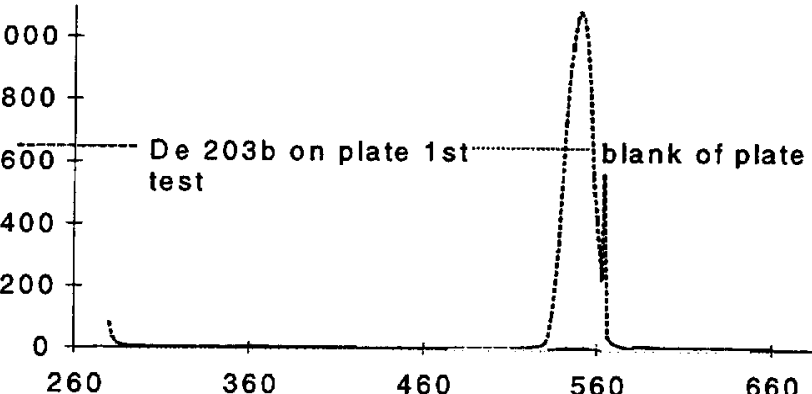

DE 203b on plate 2nd test

Two measurements at $-550 \mathrm{~nm}$ were taken to test the reproducibility of the measurements. In both cases, 50uL of the undiluted lubricant were placed on the plate and the fluorescence intensity was measured using the Farrand system 3 spectro fluorometer.

\begin{tabular}{|c|c|c|c|c|c|c|}
\hline $\mathrm{nD}$ & \multicolumn{2}{|c|}{ methanol } & plate & 1st test & plate & 2nd test \\
\hline 1.4563 & $\begin{array}{c}\lambda \max \\
+/-1 \mathrm{~nm})\end{array}$ & $\begin{array}{c}\text { fluorescence } \\
\text { intensity }(\mathrm{mV})\end{array}$ & $\begin{array}{c}\lambda \max \\
+/-2 \mathrm{~nm})\end{array}$ & $\begin{array}{c}\text { fluorescence } \\
\text { intensity } \\
(\mathrm{mV})\end{array}$ & $\begin{array}{c}\lambda \max \\
+/-2 \mathrm{~nm})\end{array}$ & $\begin{array}{c}\text { fluorescence } \\
\text { intensity } \\
(\mathrm{mV})\end{array}$ \\
\hline & 316 & 0.691 & $338-340$ & 4.3 & 544 & 40.1 \\
\hline & 632 & 0.691 & 362 & 5.1 & & \\
\hline & 830 & 0.09 & $458-460$ & 3 & & \\
\hline & & & 550 & 1088 & & \\
\hline & & & 582 & 11.2 & & \\
\hline
\end{tabular}

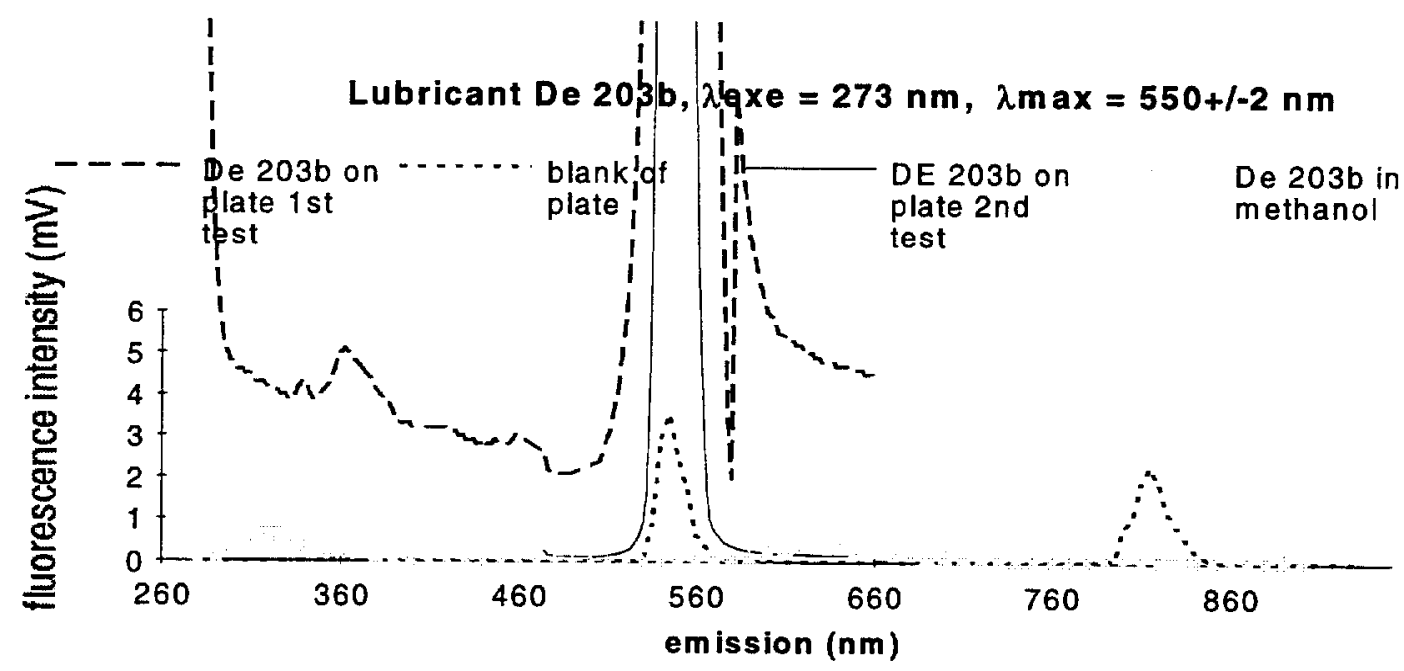

Fig. B - 2 Emission intensity for DE 203 b lubricant 
CAC $100 \lambda \operatorname{exe}=273 \mathrm{~nm}, \lambda \max =(552 \& 826) \mathrm{nm}+/-2 \mathrm{~nm}$

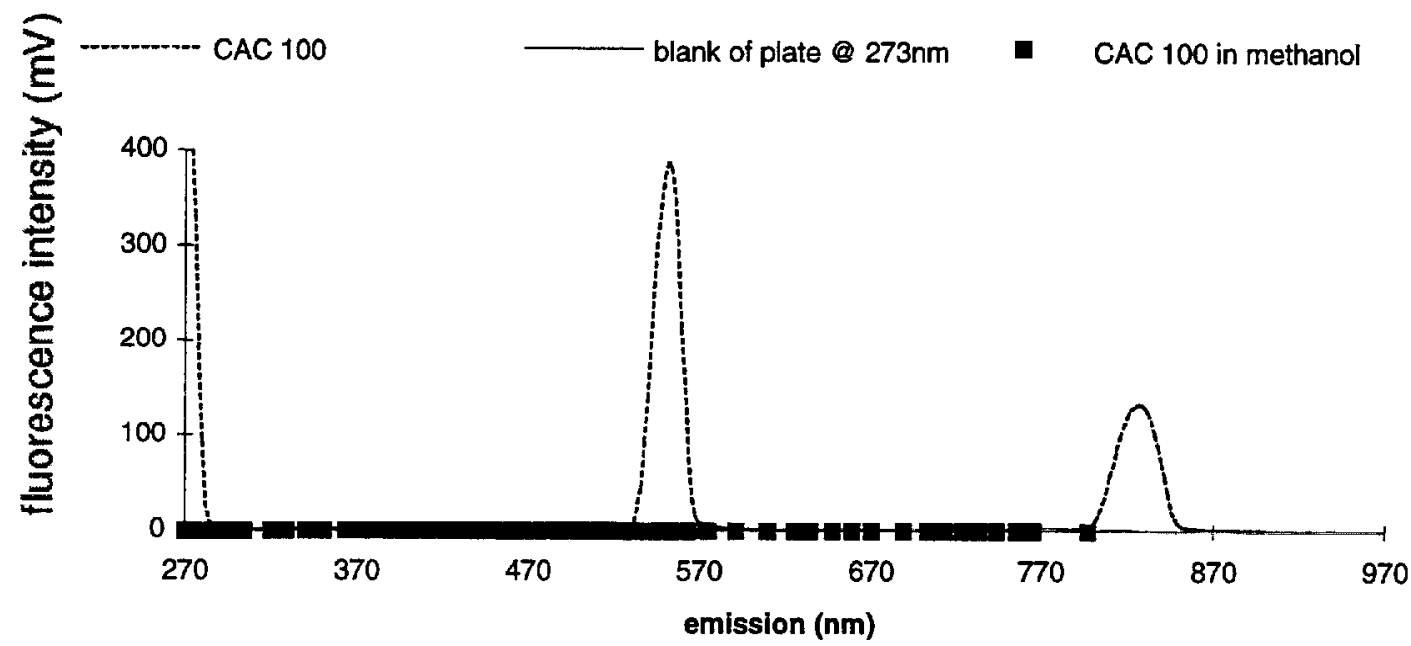

\begin{tabular}{|c|c|c|c|c|}
\hline $\mathrm{nD}$ & \multicolumn{2}{|c|}{ methanol } & \multicolumn{2}{c|}{ plate } \\
\hline 1.4552 & $\begin{array}{c}\lambda \max \\
+/-1 \mathrm{~nm})\end{array}$ & $\begin{array}{c}\text { fluorescence } \\
\text { intensity (mV) }\end{array}$ & $\begin{array}{c}\text { max } \\
+/-2 \mathrm{~nm})\end{array}$ & $\begin{array}{c}\text { fluorescence } \\
\text { intensity } \\
(\mathrm{mV})\end{array}$ \\
\hline & 320 & 0.067 & $396-404$ & 6.9 \\
\hline & 416 & 0.618 & 552 & 389 \\
\hline & $443 / 444$ & 0.736 & 784 & 3.07 \\
\hline & 798 & 0.085 & $826-828$ & 134 \\
\hline
\end{tabular}

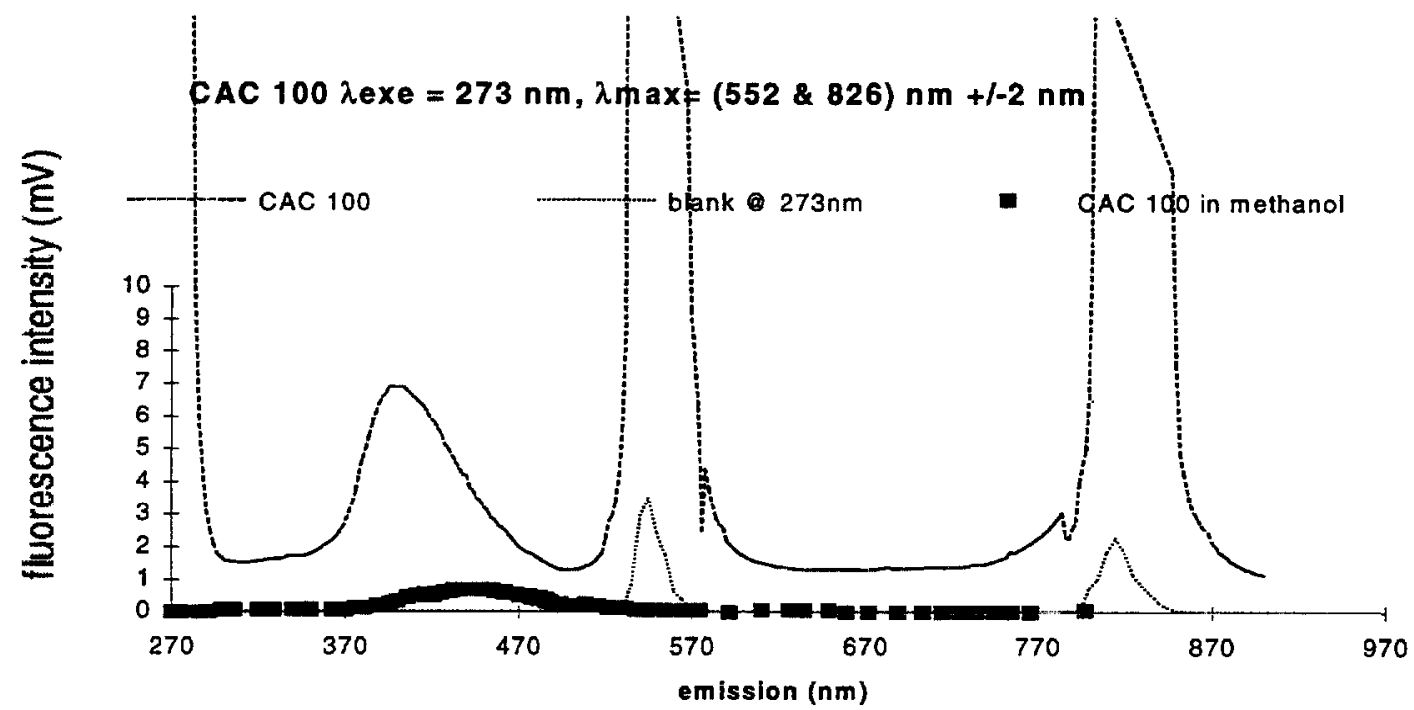

Fig. B - 3 Emission intensity of CAC 100 lubricant 


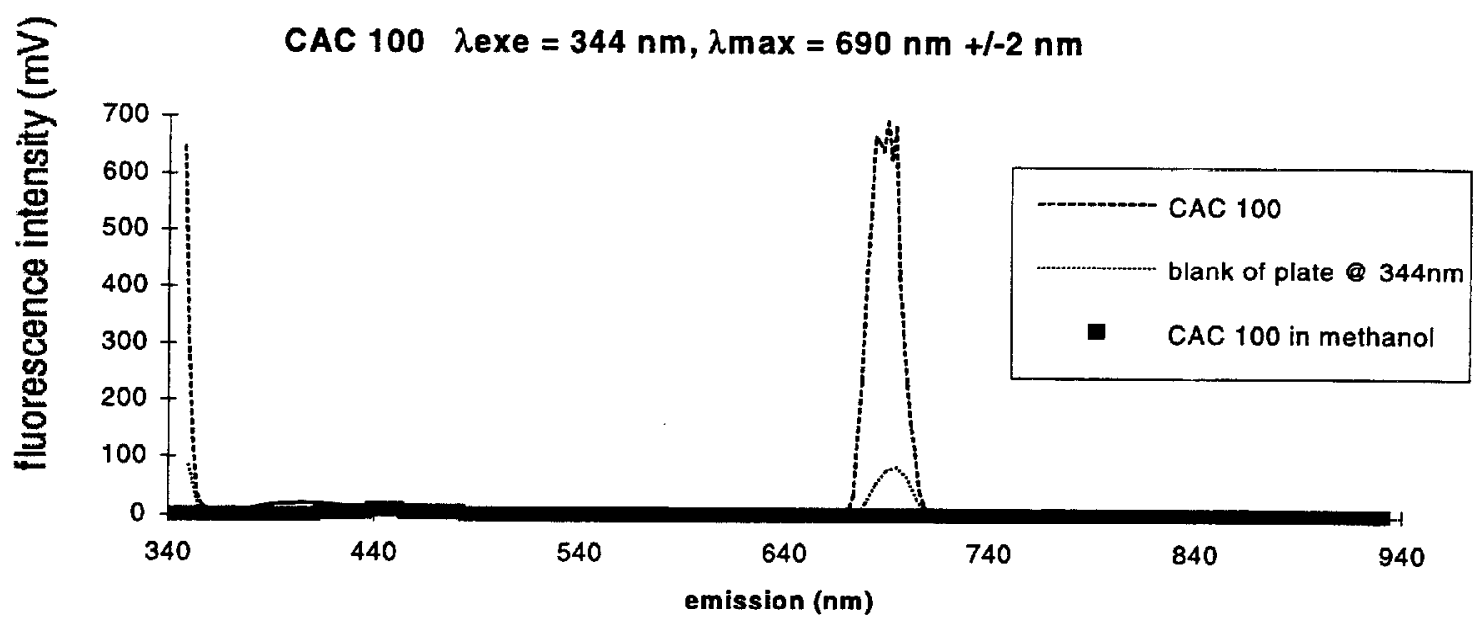

\begin{tabular}{|c|c|c|c|c|}
\hline $\mathrm{nD}$ & \multicolumn{2}{|c|}{ methanol } & \multicolumn{2}{c|}{ plate } \\
\hline 1.4552 & $\begin{array}{c}\lambda \max \\
+/-1 \mathrm{~nm})\end{array}$ & $\begin{array}{c}\text { fluorescence } \\
\text { intensity (mV) }\end{array}$ & $\begin{array}{c}\lambda \max \\
+/-2 \mathrm{~nm})\end{array}$ & $\begin{array}{c}\text { fluorescence } \\
\text { intensity } \\
(\mathrm{mV})\end{array}$ \\
\hline & 445 & 8.03 & 408 & 20.4 \\
\hline & 890 & 2.38 & 684 & 666 \\
\hline & & & 690 & 694 \\
\hline & & & 694 & 694 \\
\hline
\end{tabular}

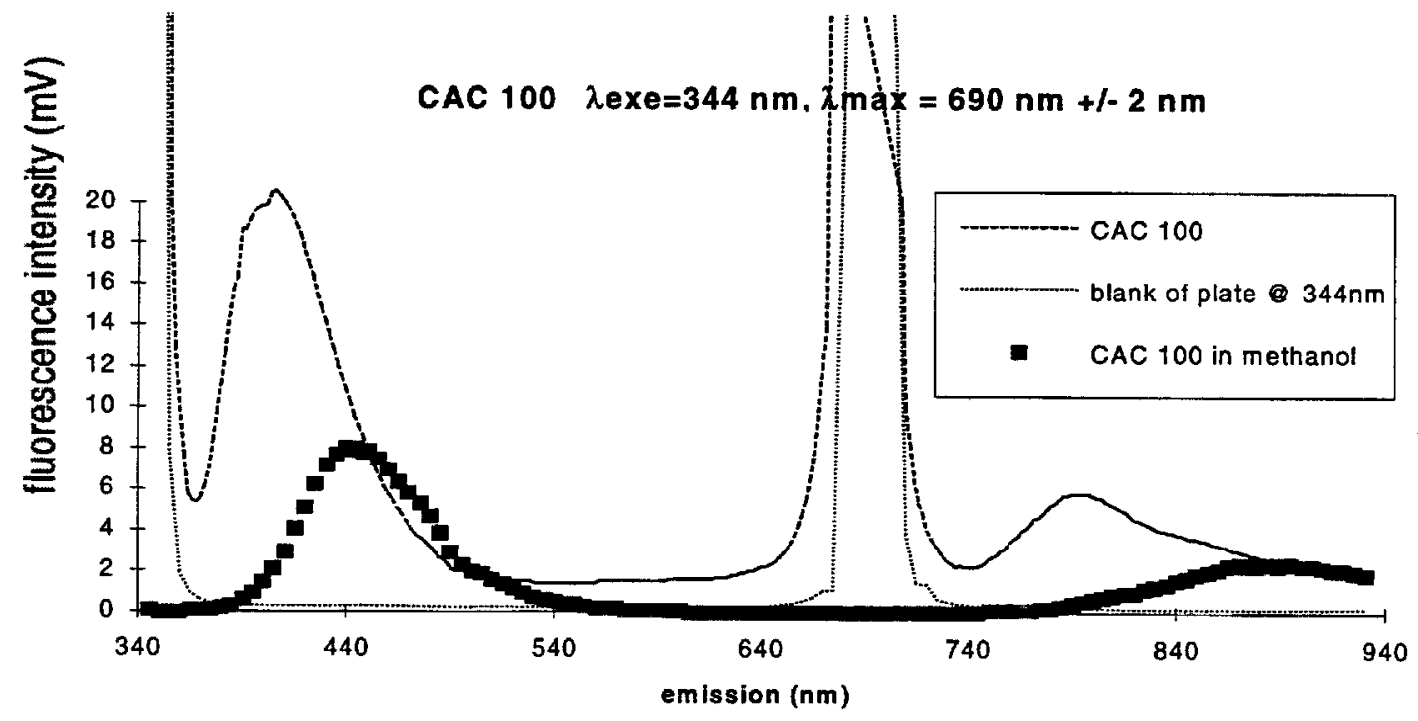

Fig. B - 4 Emission intensity of CAC 100 lubricant at $344 \mathrm{~nm}$ excitation 
Lubricant DE599 $\lambda$ exe $=274 \mathrm{~nm}, \lambda \max =(552 \& 826) \mathrm{nm}+/-2 \mathrm{~nm}$

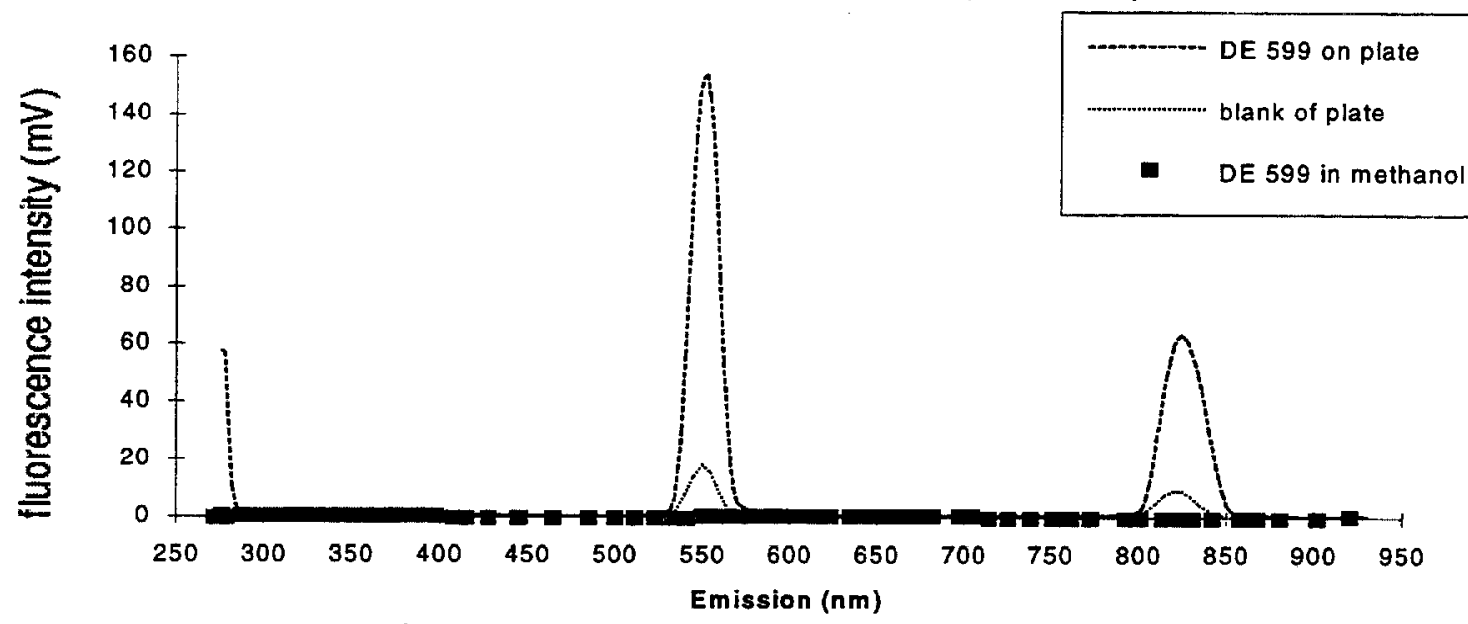

\begin{tabular}{|c|c|c|c|c|}
\hline $\mathrm{nD}$ & \multicolumn{2}{|c|}{ methanol } & \multicolumn{2}{|c|}{ plate } \\
\hline 1.4372 & $\begin{array}{c}\lambda \max \\
+/-1 \mathrm{~nm})\end{array}$ & $\begin{array}{c}\text { fluorescence } \\
\text { intensity (mV) }\end{array}$ & $\begin{array}{c}\text { max } \\
+/-2 \mathrm{~nm})\end{array}$ & $\begin{array}{c}\text { fluorescence } \\
\text { intensity } \\
(\mathrm{mV})\end{array}$ \\
\hline & 306 & 0.724 & $362-368$ & 0.72 \\
\hline & 362 & 0.45 & 552 & 154 \\
\hline & 556 & 0.3 & 826 & 63.7 \\
\hline & 609 & 0.515 & & \\
\hline & 831 & 0.141 & & \\
\hline
\end{tabular}

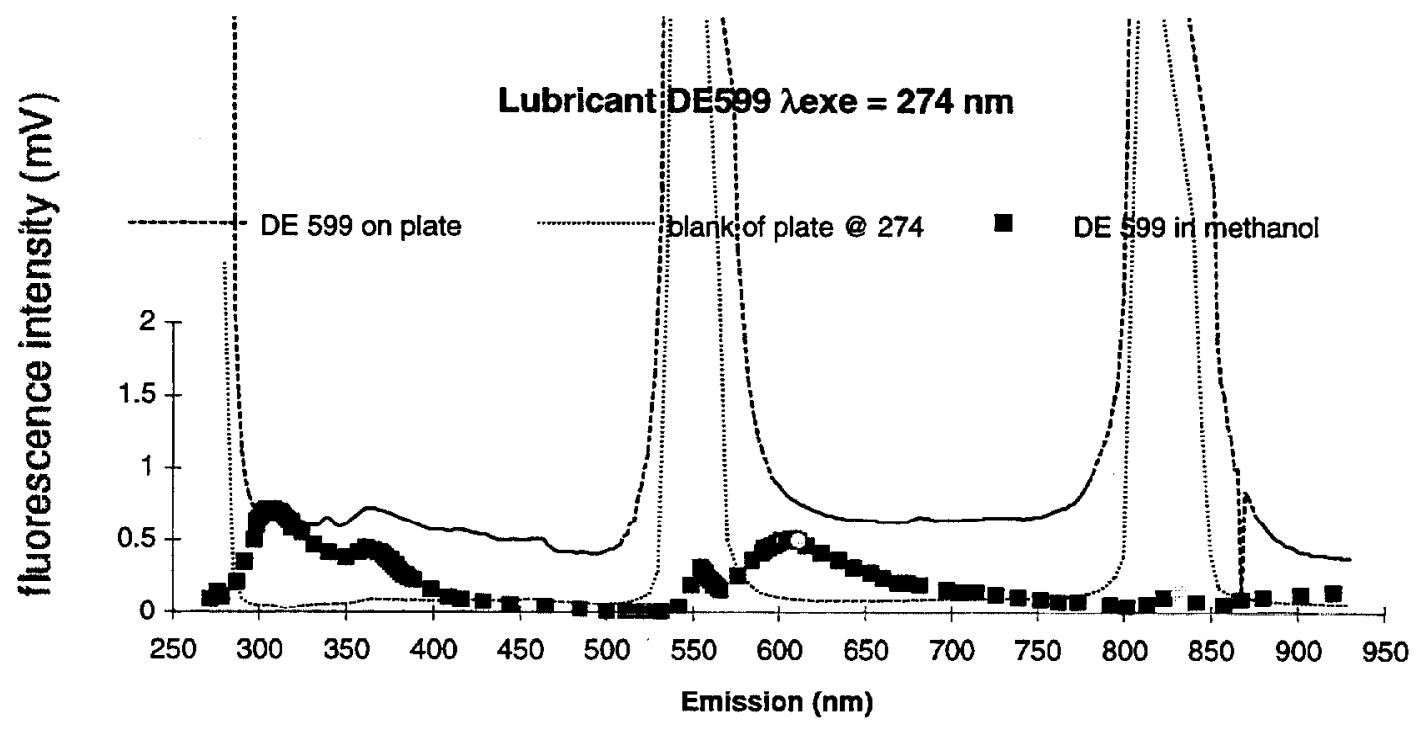

Fig. B - 5 Emission intensity of DE599 lubricant 


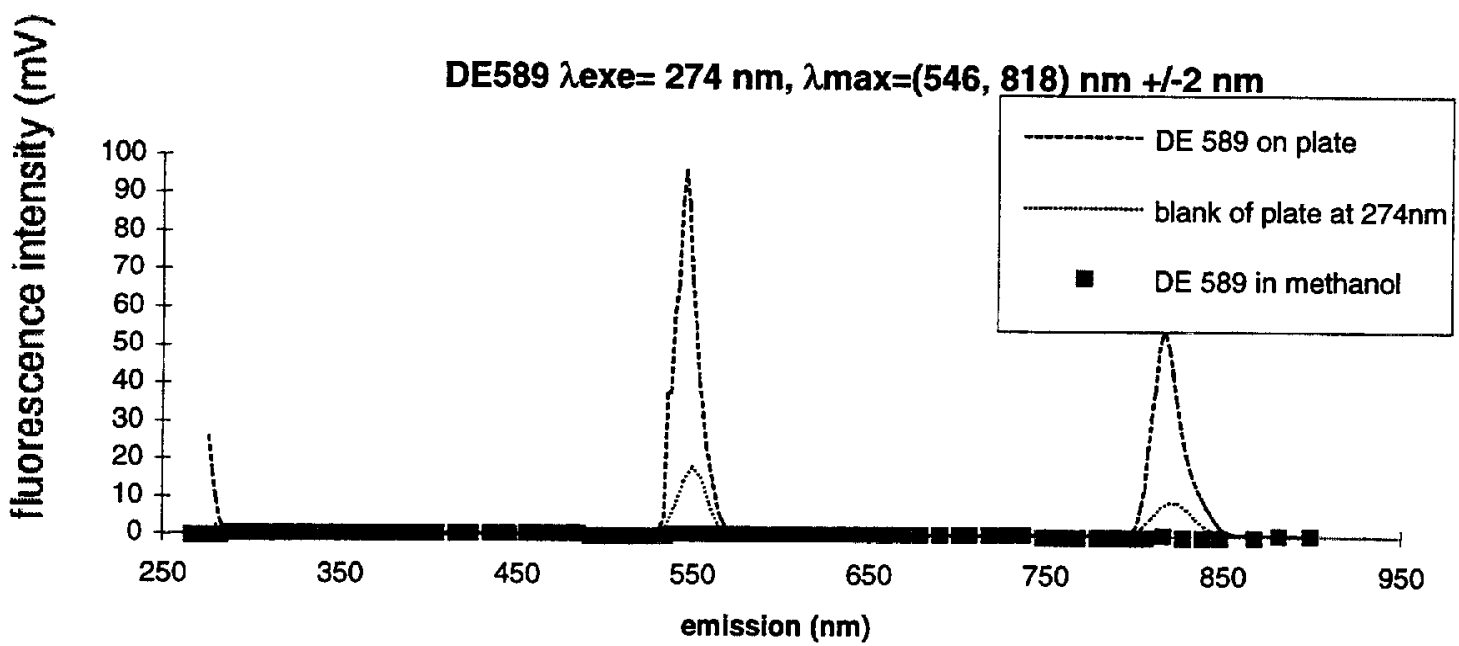

\begin{tabular}{|l|c|c|c|c|}
\hline $\mathrm{nD}$ & \multicolumn{2}{|c|}{ methanol } & \multicolumn{2}{c|}{ plate } \\
\hline 1.4529 & $\begin{array}{c}\lambda \max \\
+/-1 \mathrm{~nm})\end{array}$ & $\begin{array}{c}\text { fluorescence } \\
\text { intensity (mV) }\end{array}$ & $\begin{array}{c}\lambda \max \quad \text { ( fluorescence } \\
+/-2 \mathrm{~nm})\end{array}$ & $\begin{array}{c}\text { intensity } \\
(\mathrm{mV})\end{array}$ \\
\hline & 308 & 0.257 & 364 & 0.33 \\
\hline & 362 & 0.228 & 546 & 96.4 \\
\hline & 608 & 0.173 & 818 & 53.9 \\
\hline
\end{tabular}

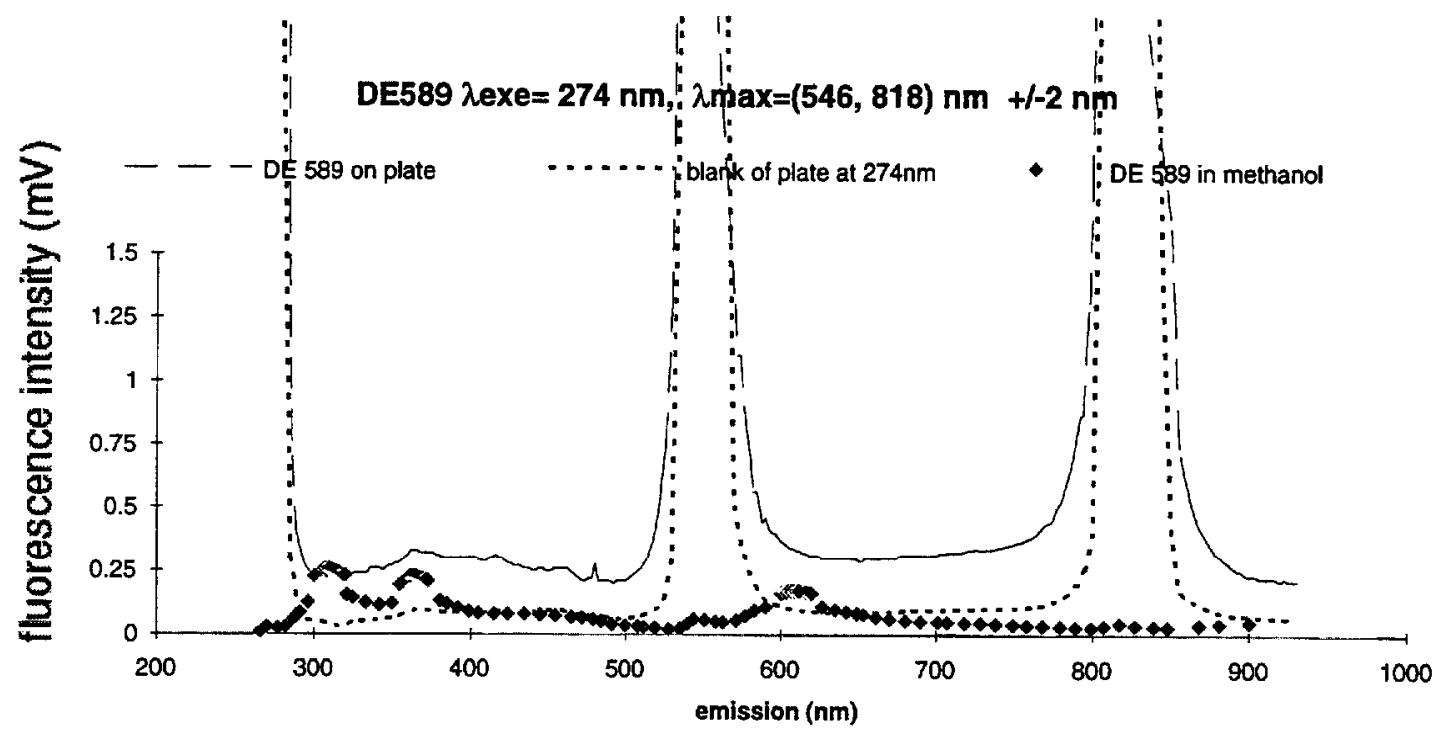

Fig. B - 6 Emission intensity of DE589 lubricant 
DE 213B $\lambda$ exe $=275 \mathrm{~nm}, \lambda \max =(546,820) \mathrm{nm}+/-2 \mathrm{~nm}$

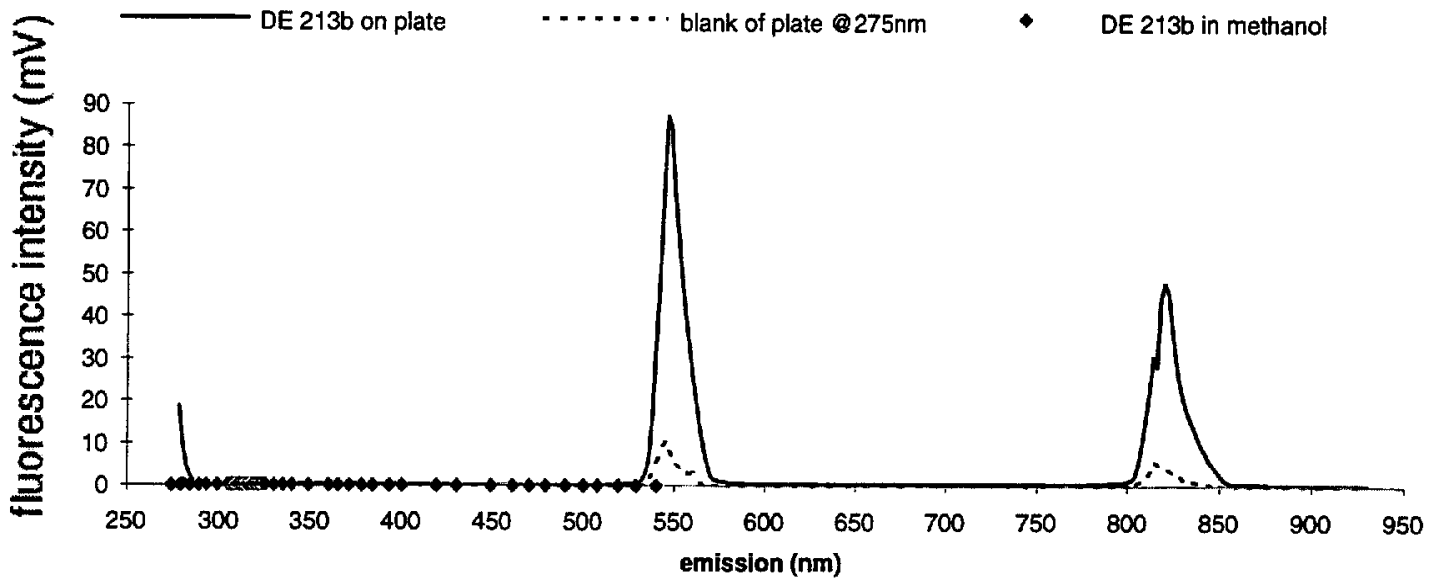

\begin{tabular}{|c|c|c|c|c|}
\hline $\mathrm{nD}$ & \multicolumn{2}{|c|}{ methanol } & \multicolumn{2}{c|}{ plate } \\
\hline 1.4546 & $\begin{array}{c}\lambda \max \\
+/-1 \mathrm{~nm})\end{array}$ & $\begin{array}{c}\text { fluorescence } \\
\text { intensity (mV) }\end{array}$ & $\begin{array}{c}\lambda \max \\
+/-2 \mathrm{~nm})\end{array}$ & $\begin{array}{c}\text { fluorescence } \\
\text { intensity } \\
(\mathrm{mV})\end{array}$ \\
\hline & $312 / 313$ & 0.148 & 362 & 0.456 \\
\hline & & & 347 & 0.495 \\
\hline & & & 396 & 0.396 \\
\hline & & & 546 & 87.5 \\
\hline & & & 820 & 48.1 \\
\hline
\end{tabular}

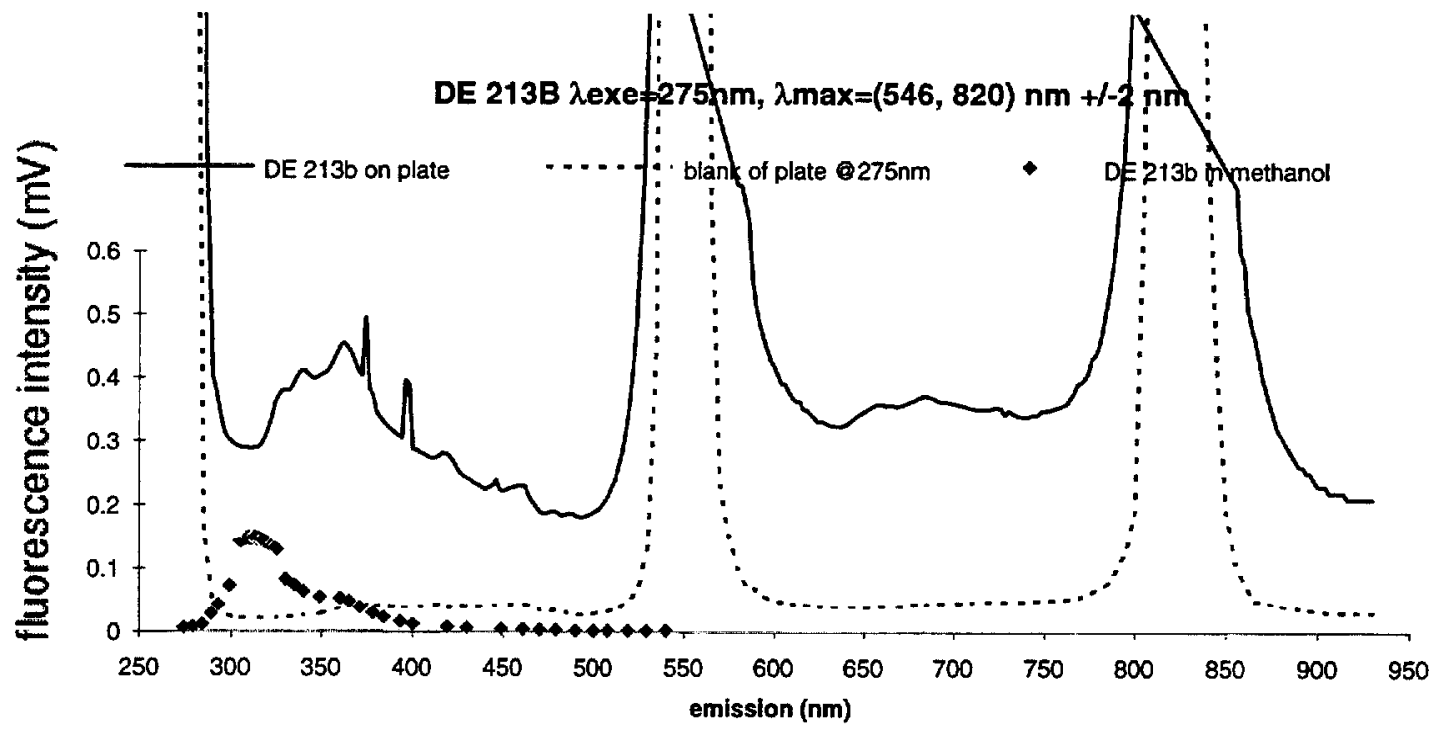

Fig. B - 7 Emission intensity of DE213B lubricant 
DGLF 118, $\lambda$ exe $=274 \mathrm{~nm}, \lambda \max =(546,816) \mathrm{nm}+/-2 \mathrm{~nm}$

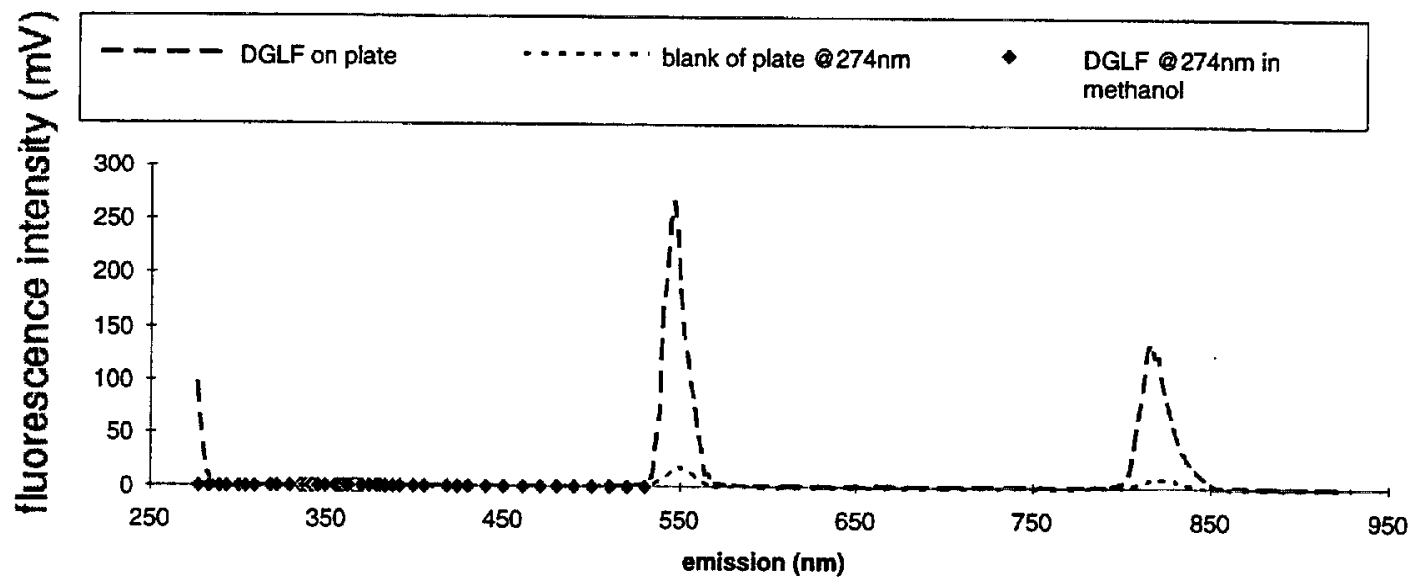

\begin{tabular}{|l|c|c|c|c|}
\hline $\mathrm{nD}$ & methanol & & plate & \\
\hline 1.4495 & $\begin{array}{c}\lambda \max \\
+/ 1 \mathrm{~nm})\end{array}$ & $\begin{array}{c}\text { fluorescence } \\
\text { intensity (mV) }\end{array}$ & $\begin{array}{c}\lambda \max \\
+/-2 \mathrm{~nm})\end{array}$ & $\begin{array}{c}\text { fluorescence } \\
\text { intensity } \\
(\mathrm{mV})\end{array}$ \\
\hline & 345 & 0.27 & 364 & 1.11 \\
\hline & $362-363$ & 0.367 & 546 & 266 \\
\hline & & & 816 & 137 \\
\hline
\end{tabular}

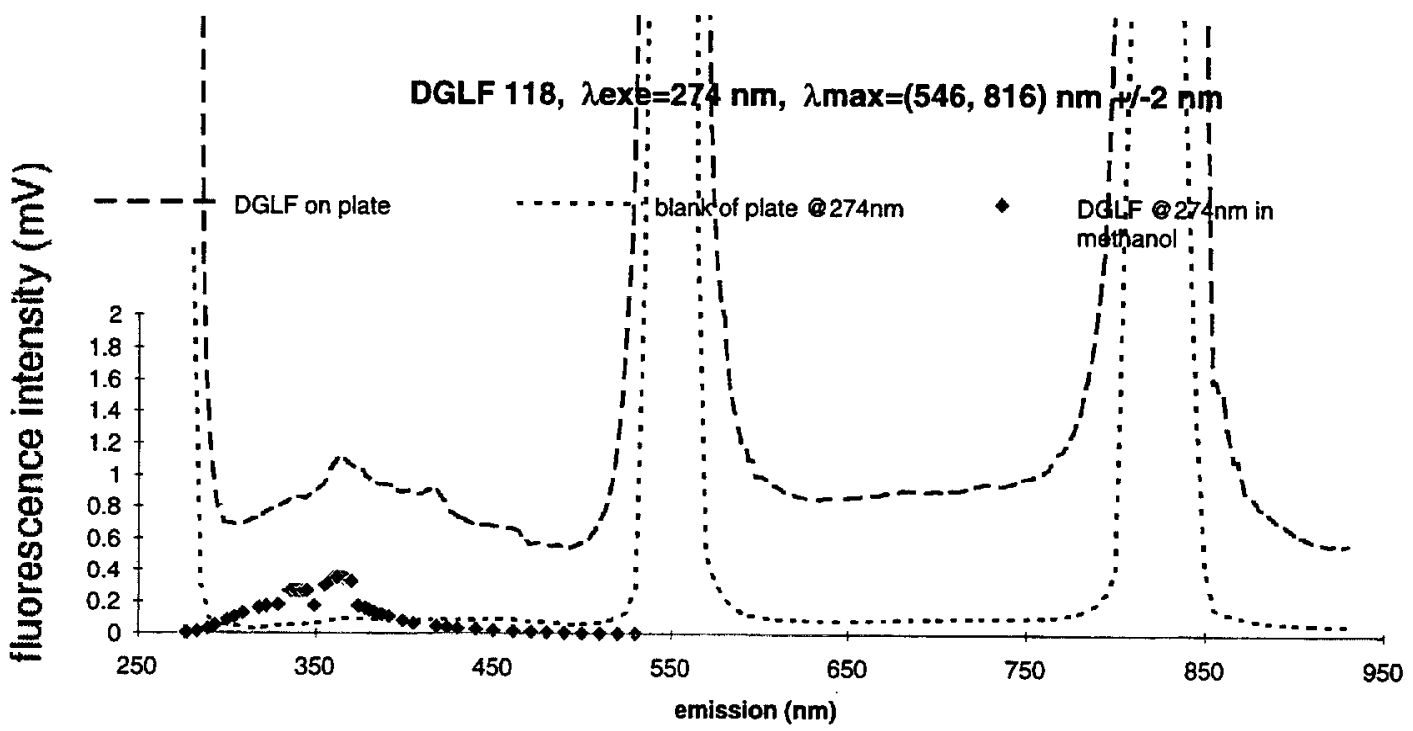

Fig. B - 8 Emission intensity of DGLF 118 
DE 601, $\lambda$ exe $=270 \mathrm{~nm}, \lambda \max =(540,808) \mathrm{nm}+/-2 \mathrm{~nm}$

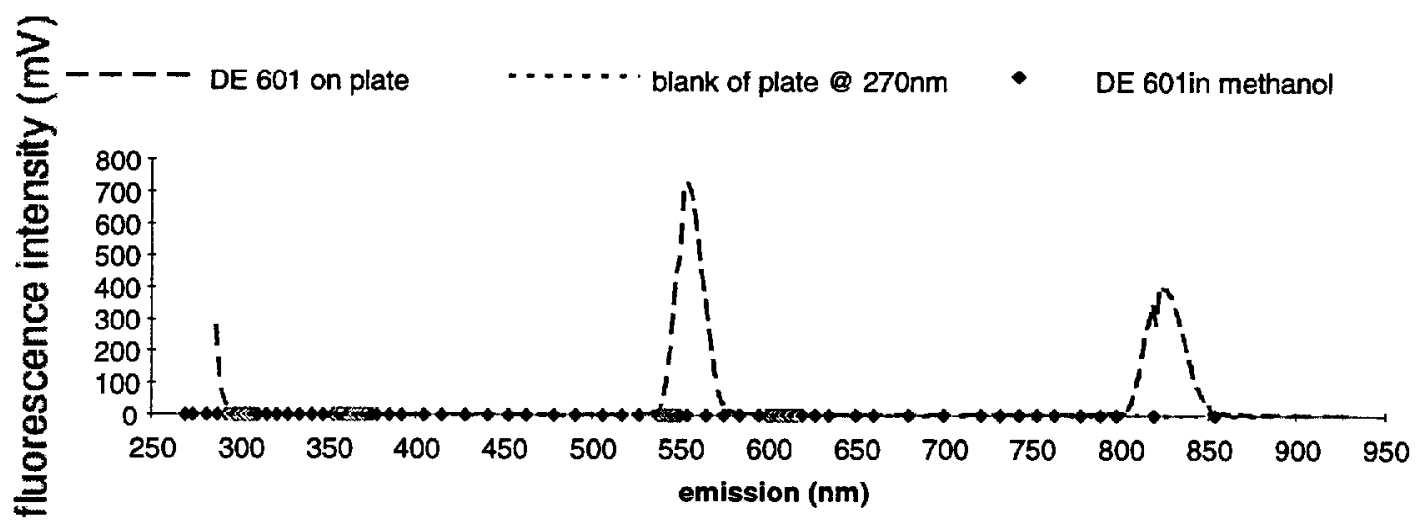

\begin{tabular}{|c|c|c|c|c|}
\hline $\mathrm{nD}$ & \multicolumn{2}{|c|}{ methanol } & \multicolumn{2}{c|}{ plate } \\
\hline 1.4549 & $\begin{array}{c}\lambda \max \\
(+/-1 \mathrm{~nm})\end{array}$ & $\begin{array}{c}\text { fluorescenc } \\
\text { e intensity } \\
(\mathrm{mV})\end{array}$ & $\begin{array}{c}\lambda \max \\
(+/-2 \\
\mathrm{nm})\end{array}$ & fluorescence intensity (mV) \\
\hline & $306-307$ & 0.3 & 286 & 4.08 \\
\hline & 364 & 0.33 & 308 & 2.74 \\
\hline & $543-545$ & 0.093 & 364 & 3.33 \\
\hline & 609 & 0.187 & 540 & 707 \\
\hline & 819 & 0.084 & 804 & 354 \\
\hline & & & 808 & 405 \\
\hline
\end{tabular}

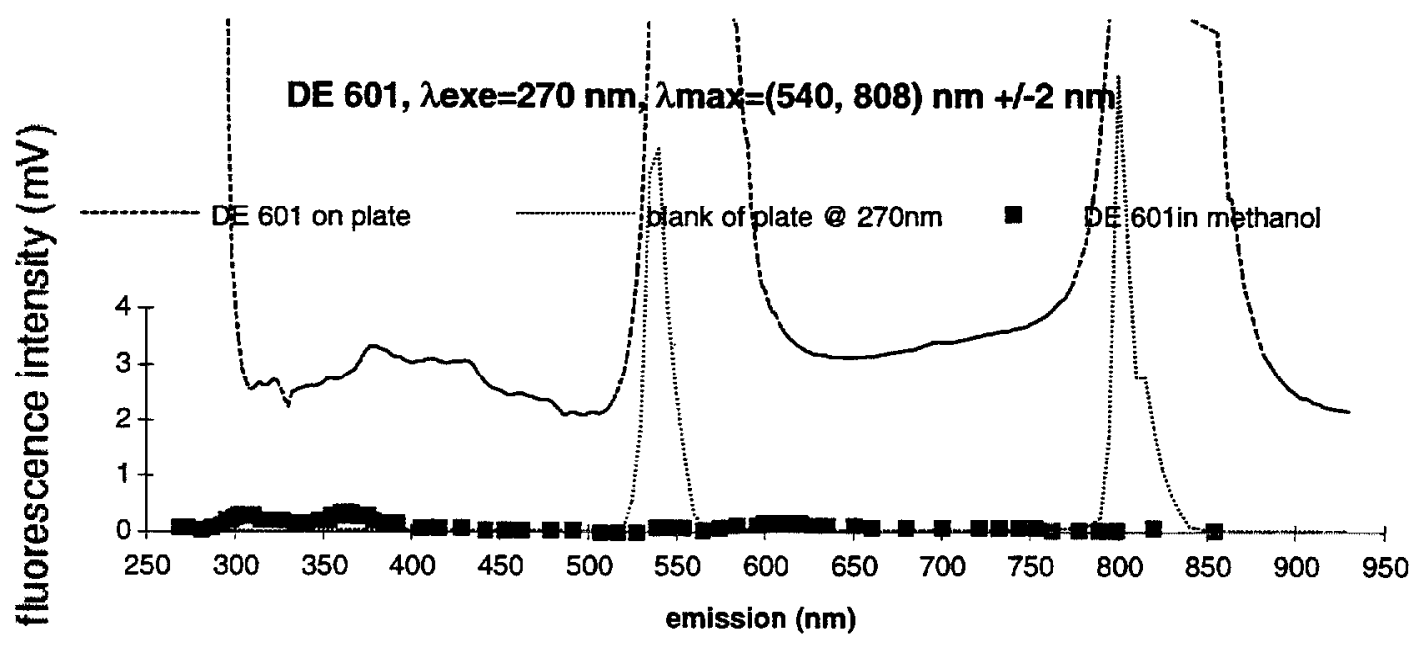

Fig. B - 9 Emission intensity of DE601 lubricant 
$D E 244 B, \lambda \operatorname{exe}=273 \mathrm{~nm}, \lambda \max =(544,816) \mathrm{nm}+/-2 \mathrm{~nm}$

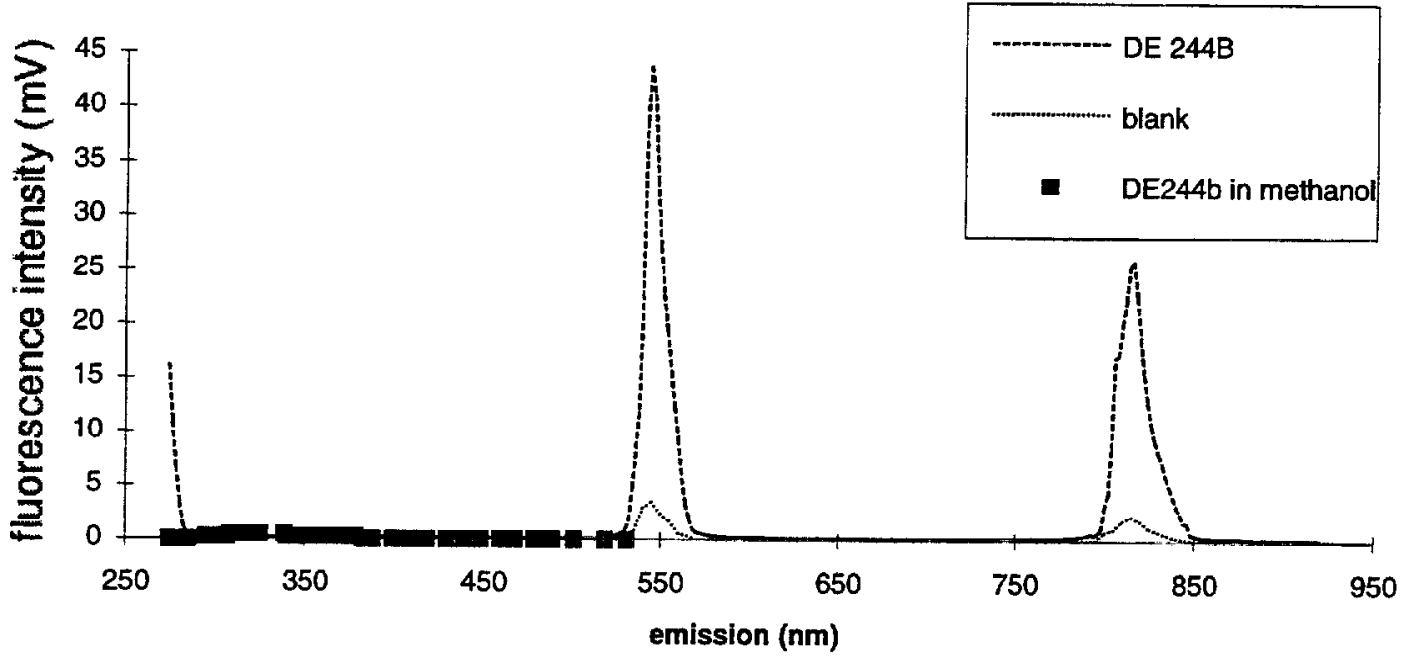

\begin{tabular}{|l|c|c|c|c|}
\hline $\mathrm{nD}$ & \multicolumn{2}{|c|}{ methanol } & \multicolumn{2}{c|}{ plate } \\
\hline 1.4542 & $\begin{array}{c}\lambda \max \\
+/-1 \mathrm{~nm})\end{array}$ & $\begin{array}{l}\text { fluorescence } \\
\text { intensity (mV) }\end{array}$ & $\begin{array}{c}\lambda \max \\
+/-2 \mathrm{~nm})\end{array}$ & $\begin{array}{c}\text { fluorescence } \\
\text { intensity } \\
(\mathrm{mV})\end{array}$ \\
\hline & 316 & 0.413 & 544 & 43.8 \\
\hline & 318 & 0.413 & 816 & 26 \\
\hline & 338 & 0.402 & & \\
\hline
\end{tabular}

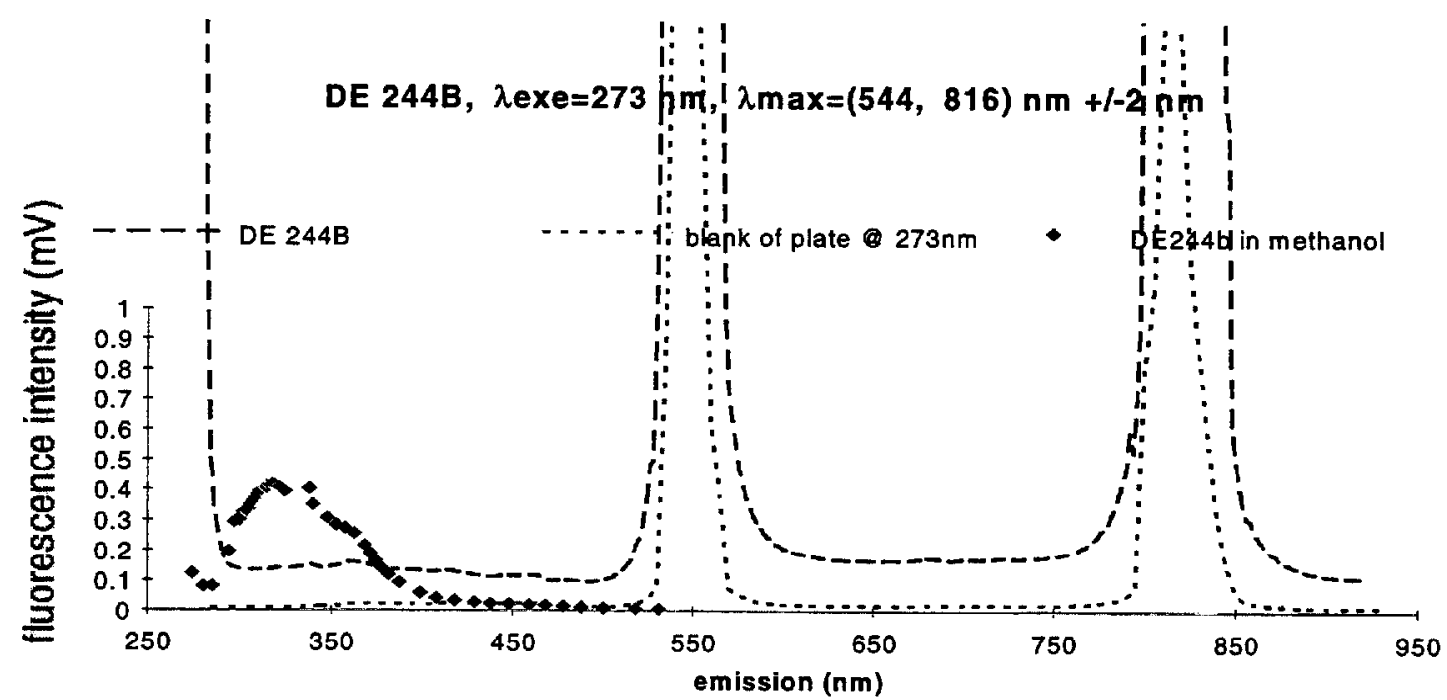

Fig. B - 10 Emission intensity of DE244B lubricant 


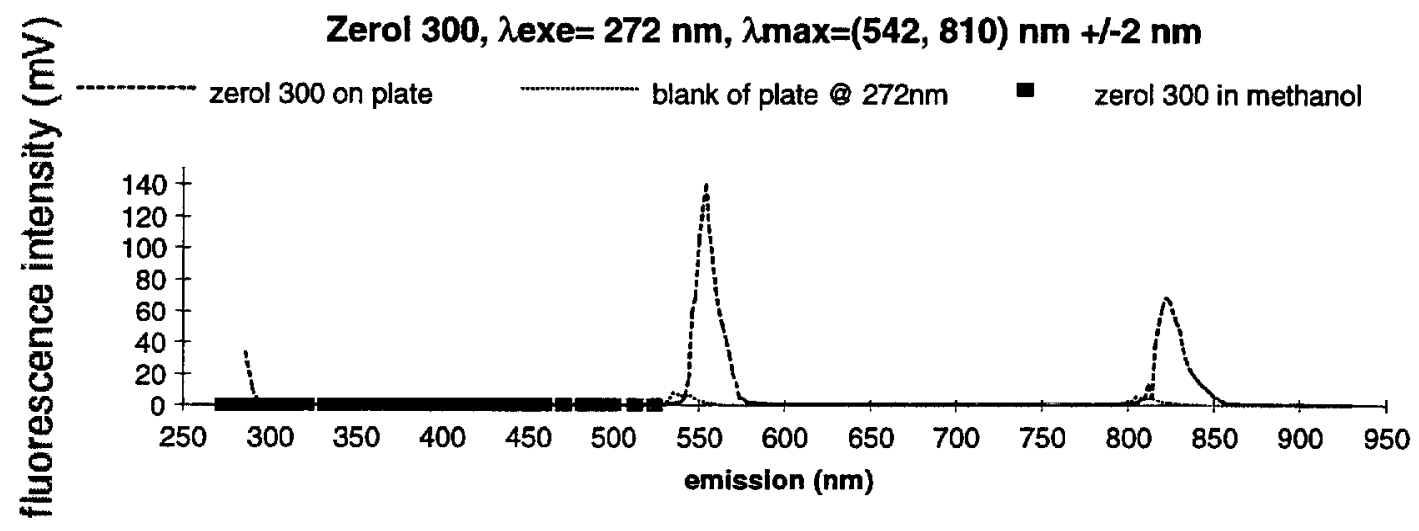

\begin{tabular}{|c|c|c|c|c|}
\hline $\mathrm{nD}$ & \multicolumn{2}{|c|}{ methanol } & \multicolumn{2}{c|}{ plate } \\
\hline 1.4893 & $\begin{array}{c}\lambda \max \\
(+/-1 \mathrm{~nm} \\
)\end{array}$ & $\begin{array}{c}\text { fluorescen } \\
\text { ce intensity } \\
(\mathrm{mV})\end{array}$ & $\begin{array}{c}\lambda \max \\
(+/-2 \mathrm{~nm} \\
)\end{array}$ & $\begin{array}{c}\text { fluorescence intensity } \\
(\mathrm{mV})\end{array}$ \\
\hline & 295 & 0.296 & 286 & 0.28 \\
\hline & 339 & 0.37 & 342 & 0.977 \\
\hline & 360 & 0.37 & 360 & 1.1 \\
\hline & & & 542 & 140 \\
\hline & & & 686 & 0.857 \\
\hline & & & 800 & 13.42 \\
\hline & & & 810 & 69.1 \\
\hline
\end{tabular}

Zerol $300, \lambda$ exe $=272 \mathrm{~nm}, \lambda \max =(542,810) \mathrm{nm}+/-2 \mathrm{~nm}$

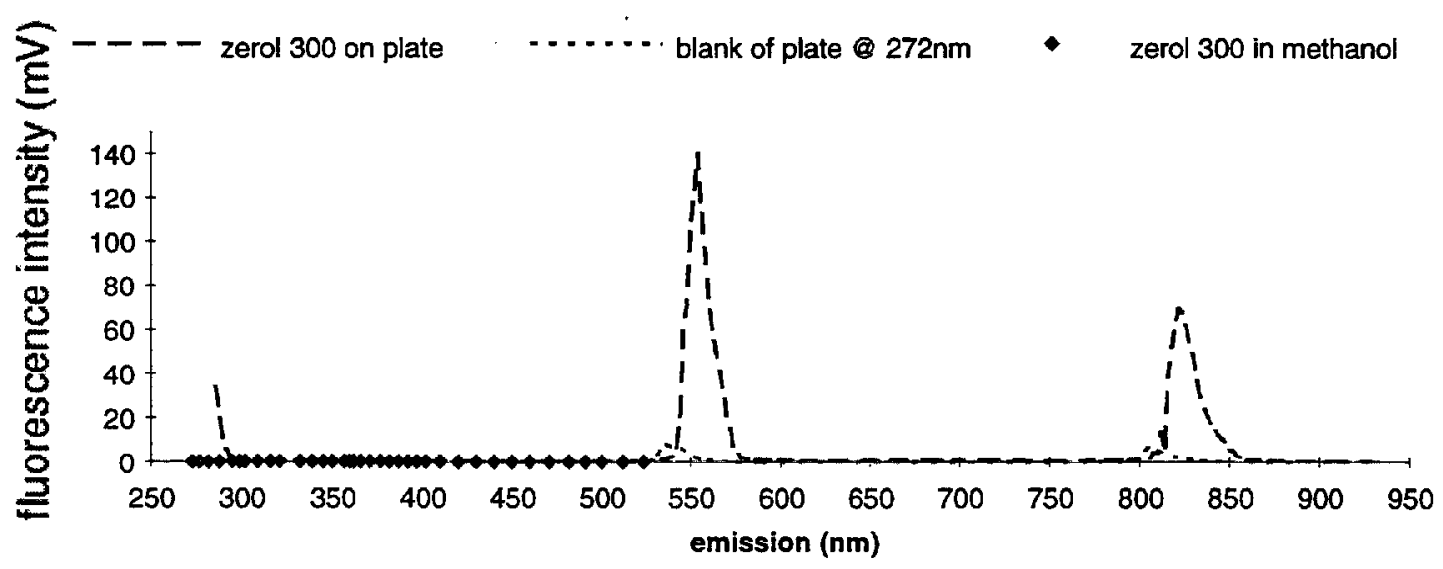

Fig. B - 11 Emission intensity of Zerol 300 lubricant 